\title{
PATENT DUCTUS ARTERIOSUS AND ITS SURGICAL TREATMENT *
}

\author{
BY \\ A. RAE GILCHRIST \\ From the Royal Infirmary, Edinburgh \\ Received October 21, 1944
}

The remarkable success that has attended surgical ligation of the patent ductus arteriosus has aroused a new interest in a unique structure and has been the means of revealing striking gaps in our knowledge of a comparatively common form of congenital heart disease. Unexpectedly, ligation of the infected ductus has shed a new light on the most serious of all forms of heart disease-bacterial endocarditis. Of vital importance in intra-uterine life, during which its purpose is to enable venous blood entering the heart from the superior vena cava to pass directly to the descending aorta and thence to the placenta without traversing the lungs (Barcroft, 1939), the arterial duct persisting after birth forms an arterio-venous fistula. Blood then flows continuously' in large quantities from the aorta to the pulmonary artery. Hence the patent ductus throws an added burden upon the heart and upon the pulmonary and to some extent the peripheral circulations.

\section{Problems of the Patent Ductus}

Despite the enormous literature that has accumulated on this branch of congenital heart disease, we have not yet adequate solutions for many of the most fundamental of its problems. Theories and suggestions to account for the closure of the ductus are many, but the factors determining the natural process of occlusion, or permitting the persistence of the channel for months or years or throughout life, are mysteries for which so far we have no entirely satisfactory explanations. Wells (1908) and Abbot (1927) have summarized the more important suggestions advanced to account for the mechanism of closure, none of which in the light of present day knowledge can be regarded as adequate without experimental proof. Expansion of the bronchi compressing the ductus, inflation of the lungs with consequent readjustment of the thoracic viscera leading to stretching and obliteration of the ductus, local thrombosis within the duct as a result of changes in blood pressure in the two circuits, the occlusive effect of a valve-like fold of aortic endothelium overlying the orifice of the channel, the constrictive effect of the recurrent laryngeal nerve as the viscera sink lower in the thorax, are among the possibilities which in the past have been advanced and seriously considered by various authors. Kennedy and Clark (1942) and Kennedy (1942) have demonstrated that during late foetal life the ductus arteriosus is an active structure, responsive to certain stimuli of which at least one favouring its prompt closure is, they believe, a rich oxygen supply either by inhalation or intravenously. By the injection of radio-opaque dye into the blood stream of fotal lambs delivered by Caesarean section, Barcroft and his collaborators $(1938,1939,1941)$ have clearly demonstrated abrupt changes in the patency of the ductus so that functionally there is a rapid obliteration of its lumen even within five minutes of birth. Anatomical obliteration is a gradual process. The factors initiating the functional or primary closure, maintaining the muscular contraction of the ductal walls, and regulating the sequence of events leading to the final obliterative process, are unknown.

Similarly there has been in the past no unanimity of opinion regarding the histological structure of the ductus arteriosus, either as found in the newborn infant or in regard to the anatomical changes leading step by step to its replacement by the ligamentum arteriosum. It is natural to correlate

* The George Alexander Gibson Lecture delivered before the Royal College of Physicians of Edinburgh on October 26, 1944. 
function with structure, the primary occlusion being doubtless attributable to twisting and contraction of the mass of muscle (Warren, 1886), arranged according to von Heyek (1935) in spiral form, which predominates in the ductal walls. Boyd (1941) has demonstrated a sensory innervation of the mammalian ductus, very similar to that possessed by the aorta and carotid sinus, derived from the left vagus nerve and also fine nerve fibres, presumably motor in type. The exact source of the latter is difficult to determine, but experiments suggest their parasympathetic origin (Barcroft, 1938).

The most recent and informative studies in the obliterative process have been made by Jager and Wollenman (1942), who have confirmed and extended the observations of Swensson (1939). The interior of the degenerating ductus is thrown into mounds, composed of scattered elastic fibres and masses of smooth muscle, which project into the lumen, increase in size and perhaps also in number, and lead ultimately to obliteration of the channel by their progressive replacement with collagen and eventually by firm fibrous tissue, the whole process of anatomical obliteration extending over several months. Alvarenga (1876) did not find a single example of perfect occlusion amongst 54 cases examined up to the age of four weeks. Christie (1930) found 65 per cent patent at the end of two weeks and 1 per cent at the end of the first year. The time of final closure therefore varies widely and no doubt accounts for the variations in histological description.

An adequate explanation for the persistence of the fotal state of the ductus is even more obscure. The occasional observation of its occurrence in more than one member of the same family suggests an inherent abnormality of the germ plasm. Smith (1929) has noted its presence in twins, and Jewesbury (1912), Ellis (1933), and Brown (1939) have discovered it in sisters. De la Camp (1903) observed a series of six brothers and sisters all with the characteristic physical signs of patent ductus arteriosus. The opportunity has been taken to examine a large number of the brothers and sisters and mothers of the children in the present series without finding another example of the condition. On the other hand, reference may here be made to Case 16, a married woman with well marked signs of patent ductus arteriosus whose mother suffered from congenital heart disease (auricular septal defect) and whose first child died from congenital heart disease. The occurrence of a congenital flaw, though each of a different type, in three generations lends support to the suggestion of an hereditary defect in the germ cell. Its common association with other congenital flaws, such as coarctation of the aorta, or the valvular atresias, or in conjunction with pulmonary atelectasis, makes it possible that a raised arterial pressure may be the factor responsible for the failure of the duct to close under such circumstances.

The gaps in our knowledge of this important congenital flaw are not confined to the basic sciences. Although 45 years have elapsed since Gibson (1898) put the diagnosis of patent ductus arteriosus on a sure foundation, it is regrettable that to this day prognosis is still largely open to conjecture. The available accounts provide insufficient information to form an accurate assessment of the natural course of the disease. The frequency of the more common complications and the rate of physical deterioration are aspects of great importance to the physician faced with the problem of estimating even on the most rough and ready basis the expectation of life for his patient. Unfortunately, the considerable literature being largely pathological, composed mostly of isolated case records and therefore weighted with the unique and exceptional, tends to distort the picture as a whole. So also the limited experience of any one observer handicaps a just assessment of the fundamental clinical problem of the influence of the untreated patent ductus arteriosus on the life span of the particular patient. Bullock et al. (1939), reviewing eighty fatal collected cases, found that 14 per cent had died by the age of 14,50 per cent by 30 , and 71 per cent by 40 . Two patients reached the age of 66 years. Similar studies led Keys and Shapiro (1943) to conclude that for those surviving to 17 patent ductus arteriosus reduced the expectation of life by about 25 years-that is, by about half. These valuable and instructive analyses are open to the criticism that the entire data have been obtained from fatal cases reported at random, which it may be argued are not strictly representative of the hazards to which living patients are exposed in that the number of survivors is unknown. Wilson and Lubschez (1942) believe that in children the surgical risks associated with ligation of the ductus far exceed the natural risk, but they admit that their series of 38 patients, considered to have uncomplicated patent ductus arteriosus, is too small to warrant absolute statements. Patent ductus arteriosus is uncommon in middle or later life and hence as a compromise it may be suggested that on the 
average the statistics of Wilson and Lubschez are probably too optimistic, just as the purely pathological data perhaps over-emphasize the gravity of the risk. Larger series of patients followed over longer periods of time ought to provide the data on which more accurate figures for life expectancy may be based. Until this has been done the problem of prognosis in untreated patent ductus arteriosus will remain unsolved.

It is in the hope of providing a better understanding of some of these problems, particularly in regard to the natural course of the disease process, that the present studies were started. Prognosis is always the immediate concern of the physician, but never more so than when faced with a revolutionary form of treatment. An experience of the untreated to balance against the results obtained by the new procedure is essential in forming a judgment, after which the method can be recommended or rejected with confidence. Preliminary findings are reported in the present paper.

\section{DiAGNOSIS}

Symptoms. Little help is to be had from a consideration of symptoms or from the build or appearance of the patient. It is more the exception than the rule to be faced with the slim, slightly built, underdeveloped, anæmic child, of a wax-like pallor and anxious countenance. To most mothers the intimation that a flaw exists in the child's heart comes as a surprise, but closer attention to the habits and reactions of the child, particularly the comparison of its behaviour with that of other members of the family at a similar age, usually leads the parents to admit, by the time age 8 or 10 is reached, that some impairment in circulatory efficiency is present. A sense of fatigue, a minor amount of breathlessness, and as the child grows older a retardation of physical development, particularly in weight and muscular development, are all features that commonly and almost imperceptibly make their appearance. Ductal patency has no specific or characteristic symptom, but the statement that it usually persists throughout childhood as a symptomless lesion is contrary to my experience. The truth of this is illustrated by the occasional observation of the mother that only after surgical ligation did she realize that previously the child had been unusually breathless. Similarly, young adults may deny any unusual degree of dyspnœa because they have become so habituated to it throughout their life as to be unaware of it. Occasionally attacks of epistaxis occur. An unusual sensitivity to cold is sometimes noted in children. Epileptiform convulsions have been described (Leech, 1932). Hoarseness from implication of the left recurrent laryngeal nerve as it rounds the aorta in the angle between the ductus and the isthmus has been recorded (Schrotter, 1901; Tileston, 1910), but is exceedingly rare. Laryngeal involvement was not observed in this series, except as a complication after operation in two patients. Cyanosis is unusual and clubbing of the fingers has not been observed. As compared with standard tables the physical development of the 13 children observed in the first decade was: above average 2, average 7, and under average 4; this agrees with the finding of Muir and Brown who noted only 5 of 20 patients to be below the standard development.

The Auscultatory Signs. The peculiar and characteristic murmur originally emphasized and described by Gibson $(1898,1900,1906)$ is of the first importance in diagn murmur, systolo-diastolic in time and best heard to the left of the upper sternum, has been described as humming, purring, tearing, churning, sawing, machinery-like, the " train-in-atunnel " sound, or as rolls of thunder. The essential feature emphasized by Gibson (1906) in his original description is its continuous quality.

"It begins," he says, " after the commencement of the first sound. It is continued during the latter part of that sound and the whole of the short pause. It persists through the second sound and dies away gradually during the long pause. The murmur is distinctly rough and thrilling. It begins softly and increases in intensity so as to reach its acme just about or immediately after the incidence of the second sound and from that point gradually wanes till its termination. The second can be heard to be loud and clanging."

Gibson drew attention to the rhythm of the thrill and murmur diagrammatically in his book (1898) and again in 1900. However debatable the justification for attaching to physical signs the name of the original observer, the custom persists and not least in the auscultatory phenomena of organic heart disease. I suggest that the pathognomonic murmur, to which 
in recent years so many descriptions have been applied, be henceforth known as the Gibson murmur. For clinical purposes it can then be described as loud (" rolling thunder "), moderate (" churning" or " machinery") or faint (" humming-top ").

As a rule in children the murmur is found maximum in the region of the second left intercostal space close to the sternum, but sometimes just below the sternal end of the left clavicle. Depending on its intensity, so may it be heard over a wide area, but usually the continuous quality is localized to a strictly limited area. It can often be heard at the back in the left interscapular region or above the spine of the scapula. On occasions it is maximum to the left of the third or fourth thoracic spine, at least in its systolic accentuation, which then suggests the presence of an associated coarctation of the aorta. As the child approaches adult life, with dilatation and elevation of the pulmonary artery and its branches within the mediastinum, the murmur commonly grows louder. The site of maximum intensity depends on the proximity of the pulmonary artery to the chest wall, and the degree and direction of the artery's dilatation. This is a gradual process. Commonly the pulmonary artery enlarges more and more to the left with the result that the murmur can then be heard over a wider area, and of greater importance from a diagnostic point of view, its maximum intensity is then often found more and more to the left of the mid-line. So much is this the case that the murmur, though loud, is located so far to the left as to be overlooked. The greatest dilatation of the pulmonary artery is commonly found when subacute bacterial endarteritis involves the vessel wall. The site of the characteristic murmur of the patent ductus may then be removed a full hand's breadth from the sternum in the second or third left interspace. Auscultation over the usual area (second space close to the sternal border) may reveal healthy sounds or no more than a long systolic murmur and an average or accentuated second sound. As the pulmonary artery enlarges the murmur must be sought farther afield.

Even in adults the continuous murmur of the patent ductus can occasionally prove exceedingly elusive. It may be so faint as to be almost inaudible and of a pitch and intensity not far removed from the breath sounds. With the patient semi-recumbent, and with breathing checked at the end of expiration, preferably just after a few full deep breaths which accentuate the murmur by increasing blood flow through the lungs, the distant hum of the Gibson murmur may then be more readily detected, though limited perhaps to an area no bigger than the bell of the stethoscope. Other auscultatory signs may accompany and overshadow the Gibson murmur and by their very intensity confuse the diagnosis. A systolic murmur is often widely heard over the præcordium, usually maximum towards the base, and accompanying it along the left sternal border; a diastolic may also occasionally be detected. These systolic and diastolic murmurs are all too apt to mislead. Neither is necessarily a result of a valvular endocarditis to which they may be attributed, particularly if insui . Ent care fails to reveal the latent Gibson hum and dilatation of the pulmonary artery. Laubry and Pezzi (1921) attribute the diastolic murmur to the pulmonary incompetence, the result of high pressure in the pulmonary artery, but the pulmonary arteries showing the maximum dilatation (e.g. Case 14) do not necessarily produce this phenomenon. With a rheumatic history the diastolic murmur suggests aortic incompetence, and with septicæmic signs a bacterial endocarditis. The pulmonary second sound is almost invariably accentuated or reduplicated-a fact of some importance in excluding other congenital flaws of the pulmonary artery. The intensity of the second sound should be studied immediately below the point of maximum intensity of the murmur.

The character of the murmur varies with the age of the patient. At birth and in infancy physical signs may be wanting. At two or three years routine examination may show a basal systolic murmur, more to the left side and radiating out below the clavicle without the intensity to suggest its organic origin. By the third or fourth year the murmur has usually developed something of a continuous quality, with systolic accentuation and maximum intensity in the pulmonary area. Signs develop with varying rapidity in different children. 
In Case 2 at the age of 4 they were fully developed (a loud Gibson murmur and thrill, and the heart enlarged), whereas in Case 17 the continuous humming quality was not detected until the age of 7 , when the child had been under observation for two years with a pulmonary systolic murmur and accentuated pulmonary second sound with dilatation of the pulmonary artery. Other examples could be quoted. As a rule the diagnosis can be made with confidence from the auscultatory signs alone by the fourth or fifth year. As age progresses the signs generally become more obvious, the murmur coarser and harsher, or they may remain stationary. Rarely they may regress or disappear entirely and leave no trace.

Radiological Examination. Radiology provides evidence of the state of the pulmonary artery and its branches. Enlargement of the pulmonary artery is usually evident in the frontal view (Fig. 1). It extends to the left as a semi-circular shadow lying between the aortic knuckle above and the ventricular mass below. One of the earliest radiological findings to be described in the examination of the heart, the bulging middle arc on the left cardiac border, has been called the X-ray cap of Zinn (1898). In the present series evidence of pulmonary dilatation was only lacking in 3 (Cases 2, 21, and 25, Fig. 2) of the 27 examined radiologically.

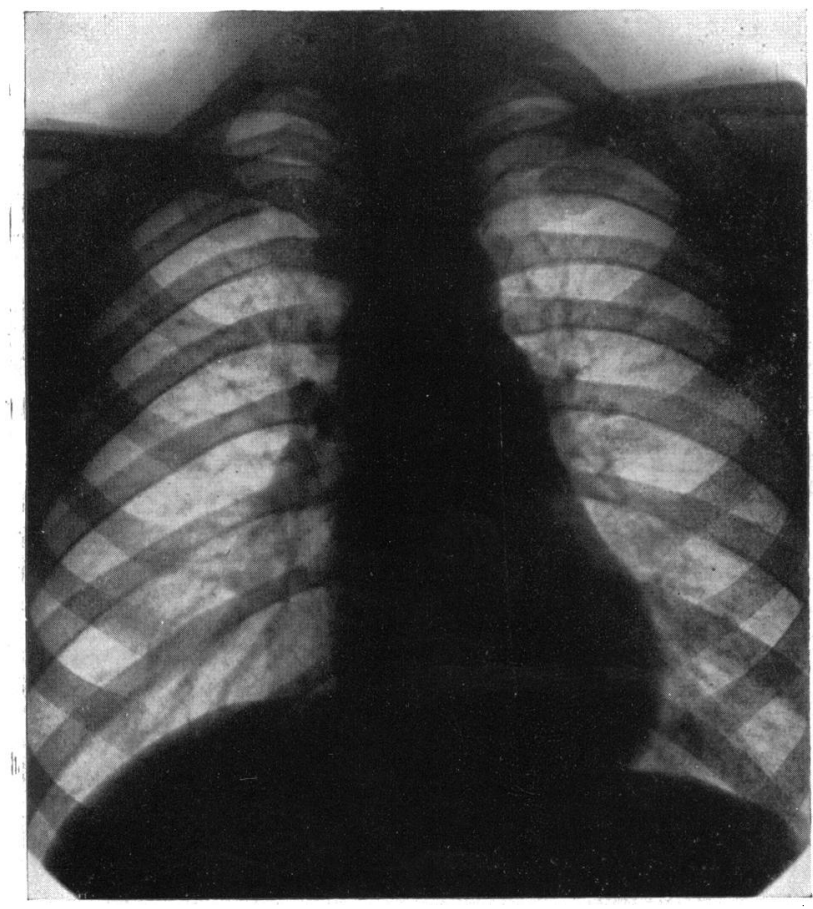

FIG. 1.-Teleradiogram. Characteristic heart outline of patent ductus arteriosus (P.D.A.) in a youth, aged 18 (Case 9). The heart size is within normal limits but the pulmonary arc makes a prominent bulge below the aortic knob. There is increased vascularity of the lung fields.

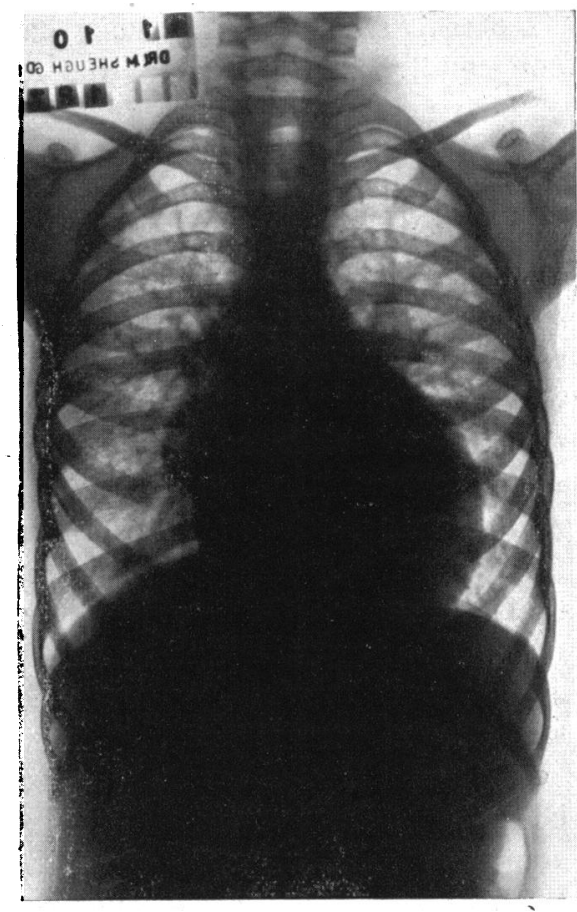

FIG. 2.-Teleradiogram. An enlarged heart in a child, aged 4, with greatly increased vascularity of the lungs, and prominent branches of the pulmonary artery, but the pulmonary arc is not prominent. P.D.A. confirmed at operation (Case 2).

In the right oblique position the trunk of the vessel can often be rendered prominent as a bulge over the upper third of the ventricular shadow. Screen examination should never be omitted. It provides visual evidence of the size of the pulmonary artery, the range of its expansion, the state of the various chambers of the heart, particularly the left ventricle, and the extent of the systolic excursion: the latter, taken with the degree of pulsation in the pulmonary artery, is almost always increased and provides useful confirmation of the nature of the defect. There are other radiological signs: dilatation of the right and left pulmonary artery branches, congestion of the lung fields as shown by a diffuse mottling radiating out 
from the hila towards the periphery, the " hilar dance ", a systolic expansion in the arteries of the lung root, and dilatation of the left auricle, the two latter being the least common in my experience-a view contrary to that expressed by Donovan, Neuhauser, and Sosman (1943), but supported by Steinberg (1943).

The size of the heart was determined according to the four grades employed clinically, and the cases studied may accordingly be grouped as follows:

(A) no enlargement-7 patients (Cases 9, 16, 19, 24, 26, 27, 28);

(B) enlarged to mid-clavicular line-15 patients (Cases 2, 4, 5, 6, 7, 8, 10, 11, 12, 13, 17, $18,21,22,25)$

(C) enlarged to within anterior axillary line-2 patients (Cases 3 and 20);

(D) enlarged beyond anterior axillary line-1 patient (Case 15);

(E) enlarged to mid-axillary line-3 patients (Cases 1, 14, 23).

Gross enlargement of the heart is therefore uncommon in uncomplicated patency of the ductus. This agrees with the opinion expressed by Roesler (1936) and others. When striking cardiac enlargement does exist it suggests complicating factors, either some other associated congenital flaw, or an infected ductus and pulmonary artery (Cases 1, 14, and 23).

Blood Pressure. Few studies have been reported on the blood pressure findings in this congenital flaw, perhaps for the reason that its diagnostic value has only recently been emphasized (Bohn, 1938). Readings have been recorded repeatedly in all the patients of the present series with the exception of one (Case 23). Blood pressure studies on healthy children are not numerous and it is often difficult to obtain reliable readings, the end point for diastolic pressure commonly lacking definition in the child. By the usual technique the sounds over the artery, brachial or popliteal, may be inaudible in the infant.

It is common to find amongst young children that the standard cuff as used in the adult is of too large a size, the edges overlapping the cubital fossa below and the shoulder above. Figures obtained under such circumstances tend to be too low, just as they tend to be too high when the standard cuff is too small a fit for the obese arm of an overweight woman. In the child, when the standard cuff appears too large for the arm, my custom is to fold it lengthwise, thereby reducing the width of the bag by half, before applying the cuff to the arm. This is a satisfactory method, yielding more accurate figures, comparable with those in the adult. According to Judson and Nicholson (1914) the diastolic pressure in healthy children between the ages of 3 and 15 ranges between 64 and 71; and the systolic between 91 and 106 . On the average a healthy child under the age of 10 has blood pressure figures in the neighbourhood of 98/68. with a pulse pressure of 30 .

Table I shows the average blood pressure for each ten-year period, minimum readings being selected for each individual. In the first decade (13 patients) the pulse pressure, as compared with healthy children of the same age, is increased as a result of a fall in the diastolic level. The numbers in the later age groups are small, but if we average the remaining 15 .

TABLE I

Average Minimal Blood Pressure in Age Groups

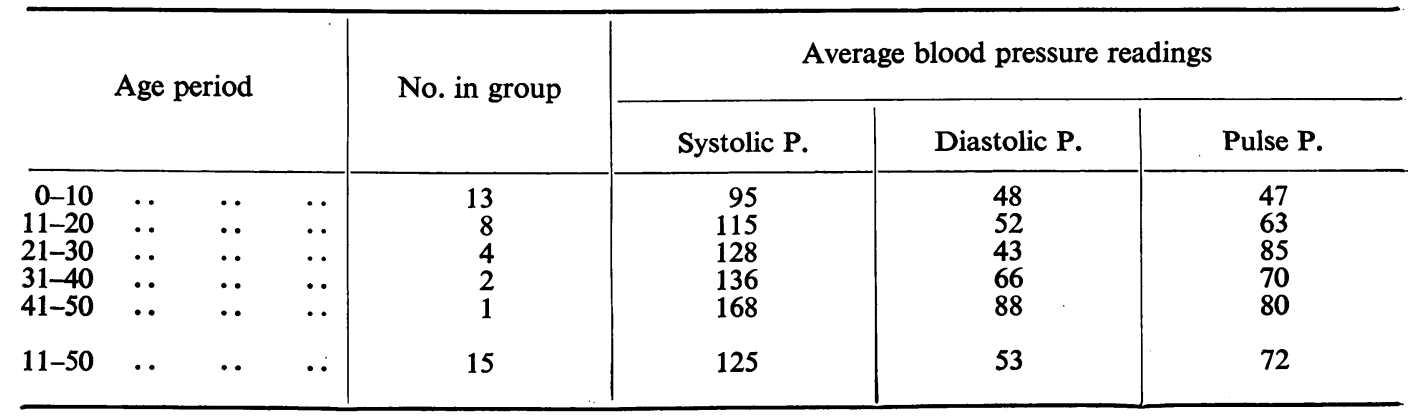


observations extending over the age period 11-50 it is found that the diastolic pressure is but little altered with age, being $53 \mathrm{~mm}$. The increase in pulse pressure $(72 \mathrm{~mm}$. for this older group) is attributable to a rise in the average of the systolic pressures $(125 \mathrm{~mm}$.). It would therefore appear that in those surviving childhood the diastolic pressure keeps fairly constant.

The level of diastolic pressure may be correlated with the size of the shunt, a ductus of larger bore being associated with a lower diastolic reading; thus the pulse pressure is a rough measure of the burden thrown on the left ventricle.

Many other factors influence the level of diastolic pressure; the peripheral resistance in the pulmonary and peripheral circuits, the elasticity of the greater vessels, the pulse rate, bodily posture, phase of respiration, metabolic state, and emotional tension, must all play a part. In the absence of satisfactory help from angiocardiography (Stewart, 1941; Steinberg, 1943) the magnitude of the leak from the peripheral circuit and the size of the ductus are probably best estimated for clinical purposes by noting the degree of the pulmonary artery dilatation, the vascularity of the lungs, and the intensity of the murmur, which presumably is influenced greatly by pressure changes within the pulmonary artery and the turbulence excited by whirling blood currents. By excluding or minimizing the influence of various extraneous factors, blood pressure readings in the basal state or during sleep may provide a rough clue to the size of the ductus, but without these precautions blood pressure readings in themselves have not been found helpful in gauging the bore of the channel. Employing simultaneous rœntgen-kymograms with acetylene rebreathing experiments, Keys and Friedell (1939) have found it possible to estimate the flow through the ductus by determinations of the right and left ventricular outputs; the method is complicated but instructive.

The Exercise Test. Bohn (1938) has pointed out the value of a simple exercise test in diagnosis. After noting the resting pressures, both of which may be perfectly normal, further readings are recorded immediately after a simple exercise test, even ten " knee-bends " being sufficient. The blood pressure must be recorded repeatedly, more than once if possible within the first minute. The systolic pressure and pulse rate may rise but the characteristic feature is the transient drop in diastolic pressure, often nearly to zero, and its prompt recovery within a minute or two. The enormous but temporary increase in the amplitude of the pulse is accompanied by tachycardia, bounding neck vessels, the Corrigan phenomenon, and capillary pulsation. Presumably under the influence of physical activity an increased shunt of blood from the aorta to the pulmonary circuit occurs as a result of vascular dilatation through the lungs. Secondly, a dilatation of the peripheral vessels, to facilitate an adequate blood supply to the active muscles, no doubt exaggerates the circulatory defect. From experience of this test, it is necessary to emphasize that the exercise must be done briskly, and to facilitate as many readings as possible within the critical first minute of completion of the muscular activity, the blood pressure cuff must be applied beforehand and worn throughout the test. Fig. 3 shows the type of reaction obtained in Case 27 : under resting conditions this man had normal blood pressure readings; exercise induces an abrupt fall to $20 \mathrm{~mm}$. in diastolic pressure.

Blood pressure readings after exercise are of particular value in diagnosis when the typical Gibson murmur is absent. Bohn (1938) believes that this can be the most important objective evidence in diagnosis. Thus in a young person a basal systolic murmur with an over-active heart and accentuation of the second pulmonary sound should not be lightly dismissed without a simple exercise test. Similarly, a raised pulse pressure in a child, lying comfortable at rest, afebrile, and without local evidence of aortic regurgitation, is very suggestive of a patent ductus arteriosus.

Peripheral Signs. There are other physical signs to be detected occasionally in the peripheral circulation. In themselves they are seldom, if ever, of help in diagnosis as their presence depends largely on a major defect itself accompanied by gross local signs readily detectable. Advanced cases, even at rest, may show most of the circulatory phenomena so commonly associated with a leaking aortic valve: facial pallor, bounding neck vessels, and the Corrigan pulse. In such instances the 


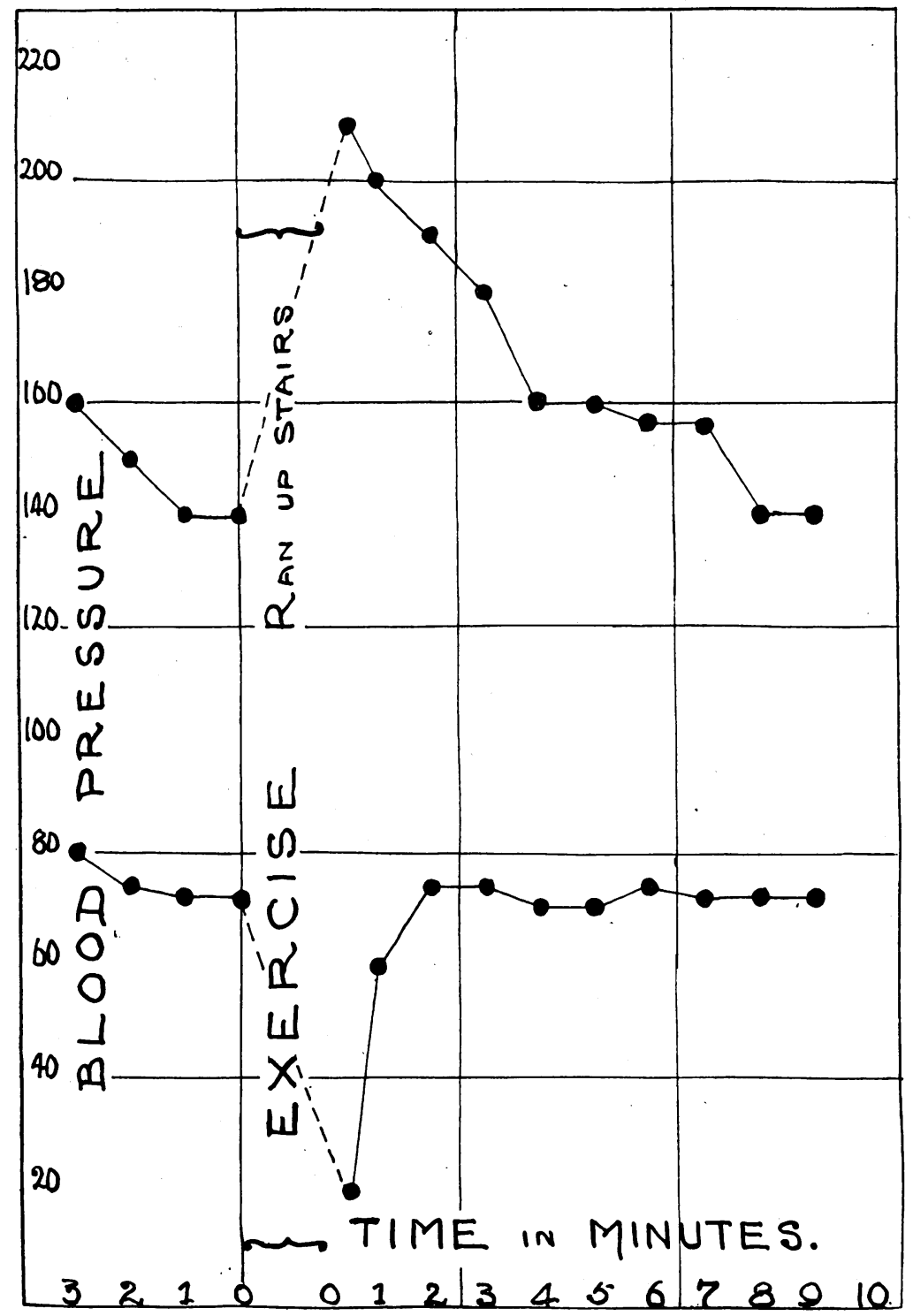

FIG. 3.-The response of the blood pressure to exercise in P.D.A. This man (Case 27) under resting conditions had normal blood pressure readings. After exercise there is an abrupt fall in diastolic pressure to $20 \mathrm{~mm}$. with prompt recovery. This reaction is of diagnostic importance.

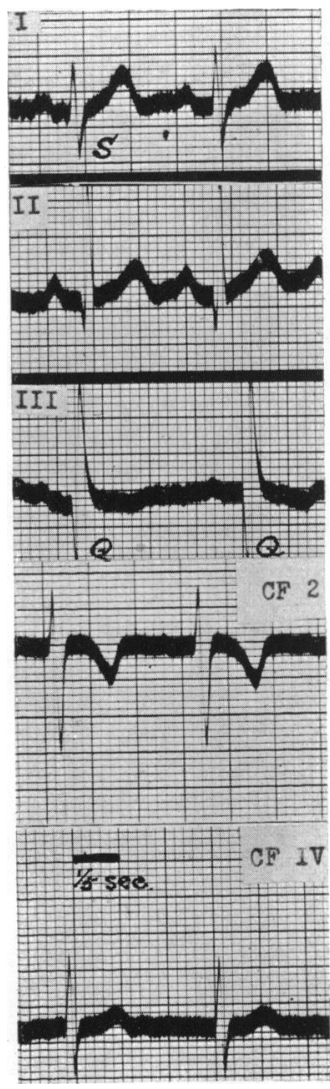

FIG. 4.-Electrocardiogram from Case 7, aged 5 years. At first glance it bears a superficial resemblance to right axis deviation, but on account of the prominent $Q$ III the curves are classified as being of the diphasic type described by Katz (1937).

communication between aorta and pulmonary artery must be large and the peripheral resistance in the pulmonary, if not also in the general circulation, considerably reduced. Franck (1878) observed a paradoxical pulse, waning with inspiration, and Hochsinger (1891) an inequality in the amplitude on the two sides. On account of the possibility of a silent or minor degree of coarctation of the aorta-this and patency of the ductus being not uncommonly associated-blood pressure readings from the popliteal arteries are useful. Laubry (1930) has noted a difference in amplitude between the femoral and radial pulses significant of some slight coarctation. Corresponding brachial and popliteal pressures were obtained in eight patients under 10 years of age, all with frank signs of patent ductus arteriosus.

In every instance (except Case 7) the pulse pressure was greater in the leg than in the arm, thus excluding the presence of a significant degree of coarctation of the aorta (Table II). The diastolic pressure in the leg was higher than in the arm as in health, with the exception of two patients-Case 12, in whom at operation the slightest degree of isthmus narrowing was observed, and Case 19, in whom the difference $(3 \mathrm{~mm}$.) is perhaps too slight to be significant. In older patients coarctation can be 
detected by radiological and other methods; but in patients under 10 , blood pressure readings in the arm and leg are the only means likely to reveal a minor degree of isthmus stenosis, rib markings, for instance, being unusual in the first decade.

TABLE II

Arm and Leg Blood Pressure in 8 Ductus Patients under 10 Years

\begin{tabular}{|c|c|c|c|c|c|c|c|}
\hline \multirow{3}{*}{ Case No. } & \multicolumn{6}{|c|}{ Blood Pressure } & \multirow{3}{*}{ Remarks } \\
\hline & \multicolumn{3}{|c|}{ Brachial artery } & \multicolumn{3}{|c|}{ Popliteal artery } & \\
\hline & Syst. P. & Diast. P. & Pulse P. & Syst. P. & Diast. P. & Pulse P. & \\
\hline $\begin{array}{r}7 \\
8 \\
11 \\
12\end{array}$ & $\begin{array}{r}88 \\
96 \\
105 \\
132\end{array}$ & $\begin{array}{l}44 \\
54 \\
45 \\
72\end{array}$ & $\begin{array}{l}44 \\
42 \\
60 \\
60\end{array}$ & $\begin{array}{l}104 \\
124 \\
125 \\
152\end{array}$ & $\begin{array}{l}? 68 * \\
64 \\
60 \\
66\end{array}$ & $\begin{array}{l}36 \\
60 \\
65 \\
86\end{array}$ & $\begin{array}{l}\text { No coarctation seen at operation. } \\
\text { No coarctation seen at operation. } \\
\text { No coarctation seen at operation. } \\
\text { Slight narrowing of isthmus seen at } \\
\text { operation. }\end{array}$ \\
\hline $\begin{array}{l}13 \\
17 \\
19 \\
21\end{array}$ & $\begin{array}{r}115 \\
108 \\
82 \\
110\end{array}$ & $\begin{array}{l}58 \\
58 \\
45 \\
45\end{array}$ & $\begin{array}{l}57 \\
50 \\
37 \\
65\end{array}$ & $\begin{array}{l}155 \\
136 \\
135 \\
130\end{array}$ & $\begin{array}{l}78 \\
68 \\
42 \\
50\end{array}$ & $\begin{array}{l}77 \\
68 \\
93 \\
80\end{array}$ & $\begin{array}{l}\text { No coarctation seen at operation. } \\
\text { Not submitted to surgery. } \\
\text { Not submitted to surgery. } \\
\text { Not submitted to surgery. }\end{array}$ \\
\hline
\end{tabular}

* An end-point difficult to determine with certainty.

The Electrocardiogram. This is generally normal in patent ductus arteriosus (Schnitker, 1940). In my series left axis deviation was observed in seven patients (Cases 1, 3, 5, 6, 9, 15, and 18), all of whom were over 10 years of age. A diphasic form of complex, described by Katz (1937) was encountered on four occasions (Cases 3, 5, 7, and 18). Latent heart block (P-R interval 0.24-0.30 sec.) was observed in one patient (Case 4). Schnitker (1940) found only one instance of right axis deviation amongst seventy. A superficial resemblance to right axis deviation is shown in Fig. 4, but the curves are atypical and are classified, on account of the prominent Q III as diphasic. Fig. 5 shows left axis deviation, abolished by operation (Case 3), and Fig. 6 depicts a complex extrasystolic arrhythmia (Case 15)-an unusual finding as the heart is almost invariably regular in rhythm. No arrhythmias were observed by Schnitker (1940). It can therefore be said with Drawe (1937) that in diagnosis a normal or
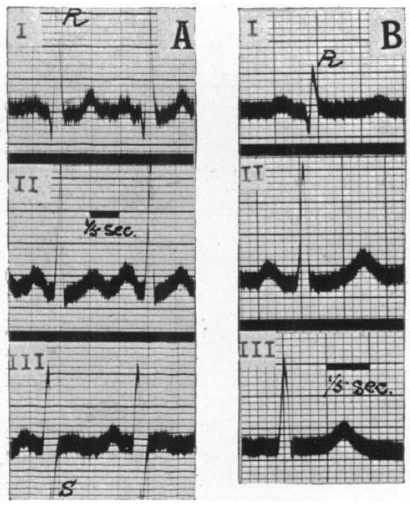

Fig. 5.-Electrocardiogram from Case 3. (A) Recorded before operation, shows well marked left axis deviation; (B) recorded $3 \frac{1}{2}$ years after surgical ligation of P.D.A., shows loss of axis deviation, disappearance of S III, and diminution of $\mathbf{R} \mathbf{I}$.

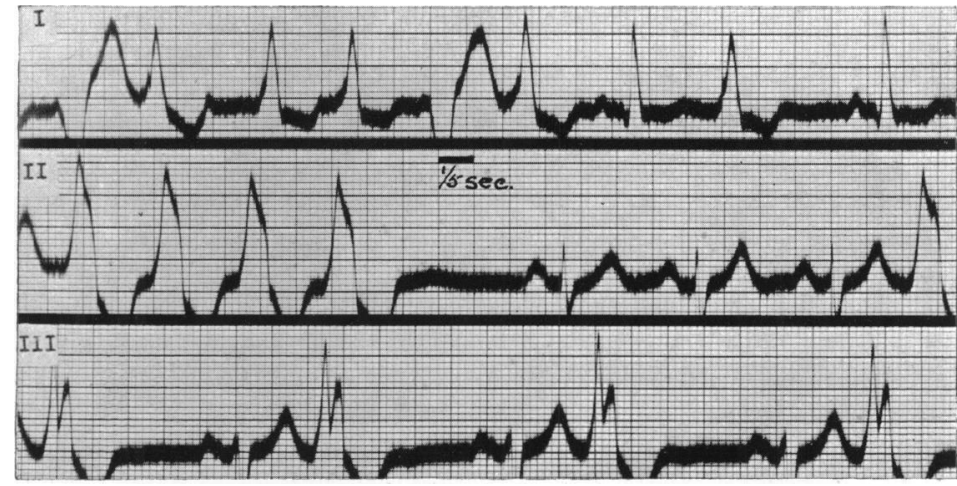

FIG. 6.-Electrocardiogram from Case 15 shows complex extrasystolic arrhythmia, with runs of coupled rhythm and occasional ventricular paroxysms - a most unusual finding in the presence of P.D.A., in which the heart rhythm is almost always regular. 
almost normal cardiogram favours a patent ductus arteriosus. Certainly the absence of right axis deviation is of help in excluding the presence of pulmonary stenosis, in which it is the rule (Alexander, Knight, and White, 1925).

Diagnostic Criteria. Particular emphasis has been placed on the importance of the auscultatory signs. To the trained ear diagnosis is simple, but even in the absence of the pathognomonic Gibson murmur the diagnosis can still be established with some justification if other signs are present. Amongst these, in order of importance, are: (1) an increased size and excursion of the main trunk of the pulmonary artery on radioscopy, (2) an increased pulse pressure at rest or induced or aggravated by the exercise test, and (3) a long, harsh systolic murmur maximum below the inner end of the left clavicle. This bruit in a child or young person, particularly when accompanied by a reduplicated or accentuated second pulmonary sound, should always arouse suspicions. The other physical signs-the thrill that accompanies the rougher murmurs, Gerhardt's ribbon dullness (an unreliable clinical sign of pulmonary artery dilatation incapable of revealing the minor degree of enlargement) and the pulsus paradoxus-are of much less importance as they are only found when the essential signs enumerated above are so striking as themselves to make the diagnosis obvious.

\section{Differential Diagnosis}

Reference has already been made to certain aspects of differential diagnosis. It is worth emphasizing that both pathological statistics (Bullock, 1939) and clinical experience indicate that after the first year of life has been passed other congenital cardiac defects are seldom found to accompany patent ductus arteriosus. Abbott's (1936) studies indicate that when the flow of blood through the ductus is a compensatory phenomenon for some other major congenital flaw, cyanosis is the almost invariable rule. Such defects as bicuspid aortic valves, or even patency of the interventricular septum, which may pass undetected, are not contraindications to ligation. On the other hand, the failure to recognize the presence of a coarctation of the aorta is more regrettable. Ligation done in the presence of multiple defects cannot be expected to produce as satisfactory results. It may indeed prove harmful.

The congenital heart lesions likely to cause confusion are those accompanied either by basal systolic murmurs or by enlargement of the pulmonary artery. A harsh systolic murmur maximum in the second left space without cyanosis or clubbing and accompanied by a distinct second pulmonary sound, makes the presence of a congenital pulmonary stenosis most unlikely, for as pointed out by Muir and Brown (1932) in this latter condition the pulmonary second sound is as a rule weak or absent, although an accentuated sound has been observed on occasions (Eakin, 1929). If in doubt the fall in diastolic pressure induced by an exercise test will favour a patent ductus. Radiological examination is also helpful, attention being directed to the size and shape of the heart and the vigour and extent of the systolic excursion. Exaggeration of the cardiac pulsation occurs in a number of conditions. It is found in hyperthyroidism, in which the heart action has been described as "jittery" in character and affecting all the chambers, and also in aortic regurgitation, which imparts a distinctive rocking movement to the heart as a whole, with increased pulsation in the aortic notch (Donovan, 1943).

On the other hand, the enlargement of the pulmonary artery and its branches, so characteristic of auricular septal defect, may give rise to difficulty if the Gibson murmur is obscure or doubtful. This is accompanied by right ventricular hypertrophy, a shadow of the caur-ensabot type, right axis deviation, low blood pressure, and an absence of the circulatory phenomena of a low peripheral resistance. Similar findings help to exclude Fallot's tetralogy, Eisenmenger's complex, and Lutembacher's syndrome, in all of which cyanosis is commonly found. Graham (1940) has described how an aneurysm of the ductus arteriosus may readily be mistaken for a mediastinal tumour. The clinical history, the response of the blood 
pressure to exercise, and screen examination, should help in the differentiation, if the Gibson murmur is absent.

The differentiation of ventricular septal defect is based chiefly on the site of the murmur, maximum in the third or fourth left space, and the absence of notable pulmonary artery enlargement. Schnitker (1940) has noted the presence of a steep S wave in leads I and II, but this is not supported by Brown's (1939) findings in Maladie de Roger.

Congenital defects of the aortic septum, consisting in a communication between the first part of the aorta and the pulmonary artery, above or below the cusps, are most uncommon but give rise to signs almost indistinguishable from those of a patent ductus arteriosus. Brown (1939) points out that the continuous murmur of the aortic defect tends to be maximum a little lower in the chest than the Gibson murmur. It is also louder, coarser, and more superficial, and the heart itself tends to be larger than that commonly found in the presence of uncomplicated patent ductus arteriosus. Cases of this type have been described by Fraentzel (1866) and Oberwinter (1904). One case has been explored in mistake for a patent ductus arteriosus but the surgeon had the good judgment to retreat without attempting ligation (Shapiro and Keys, 1943).

From acquired lesions-rheumatic or syphilitic-difficulty in differentiation seldom arises, though if the humming-top murmur is unusually faint and the diastolic element predominates and is, as sometimes happens, conducted down the sternum, some confusion may well arise. The site of maximum intensity, the dilated and pulsatile pulmonary artery, the vascular increase through the lung fields and the clinical history, should prove helpful in establishing the diagnosis of patent ductus arteriosus.

Functional and hæmic murmurs differ from ductal and other organic murmurs in their soft, blowing character. The benign murmur varies greatly with a change in the position of the patient, and with the phase of respiration. Hæmoglobin determinations, correction of the anæmia if present, and employment of the exercise test already described should readily differentiate these from the systolic murmur that commonly precedes the appearance of the fully developed ductal murmur.

In children a venous hum, without pathological significance, is occasionally heard in the root of the neck. It causes a continuous murmur, sometimes associated with a thrill (Hubbard, 1943), maximum above the clavicle. It is abolished by jugular compression, which has no influence on the Gibson murmur, and similarly a change of posture may cause this benign murmur to diminish or disappear altogether.

In general it may be said that difficulties in differential diagnosis seldom arise. Other congenital lesions can usually be excluded by simple clinical observations, and acquired heart disease presents as a rule a very different picture.

\section{The NATURe OF THE Defect}

Although originally described by Galen as a short vessel uniting aorta and pulmonary artery, the ductus arteriosus has erroneously been associated with the name of Botallo. Franklin (1941) in a scholarly review of the classical literature has suggested an explanation for the mistake commonly perpetuated in the German writings. Misled largely as a result of an illustration inserted by van Horne in his edited edition of Botallo's complete works. (1660), and confused by a superficial acquaintance with the original Latin text, subsequent writers have repeated the error. Botallo has no claim to the ductus and van Horne's illustration, reproduced in Fig. 7, is itself incorrect anatomically.

The ductus at birth is a short channel about $10 \mathrm{~mm}$. in length and $5 \mathrm{~mm}$. in width, wider indeed than generally assumed as it is equal to or greater in calibre than the aortic arch or pulmonary artery or descending aorta (Noback and Rehman, 1941). Its function was known to Harvey (1628), but it is only in recent years that exact observations have been made on the nature of the disturbance imposed on the circulation by its persistence. 
68

Figuræ prim $x$ Explicatio.

A A A. Filx.

bbbb. Sinus falcis fuperior, feulongitsdinalis, apertus. C Officulum maximum. D. aliud predscio minus.

if Duo exigua offecsha, fatis tamen acuminata.

Figuræ fecundæe Explicatio.

A. Cor.

B. Aurichla dextra aperta.

C C. Vena Cava fimiliter diffecia.

D. Foramen vens coronaria

E. Foramen ovale, per quod fanguis in auricklam finiftram tendits.

F. Valvula eidem foramini appofita.

Figuræ tertix Explicatio.

A. Cor.

$B$ B. Pulmones.

C C. Arteris corta afcendens.

$D$ D. Arteria Truncus de feendens.

E E. Arteria pulmonalis, feu Vena arteriofa dizas.

$F F$. Canales aे pulmonali arteria tendens in aortam.

venofam, quæ \& fi fruftra olim perquifiverim, nuper tamen denuò eidem inquifitioni me tradens, cor dividere occepi, ubi paulò fupra

vas facilè refupinaretur, quo guis rurfum in venami cavam fangurni à vena cava cum reverteretur. Moxadjungit", imperu affluenti cederet qui- (uperat omnem admirationem, dem, probiberts autem ne jan-predigi foraminis basd. its

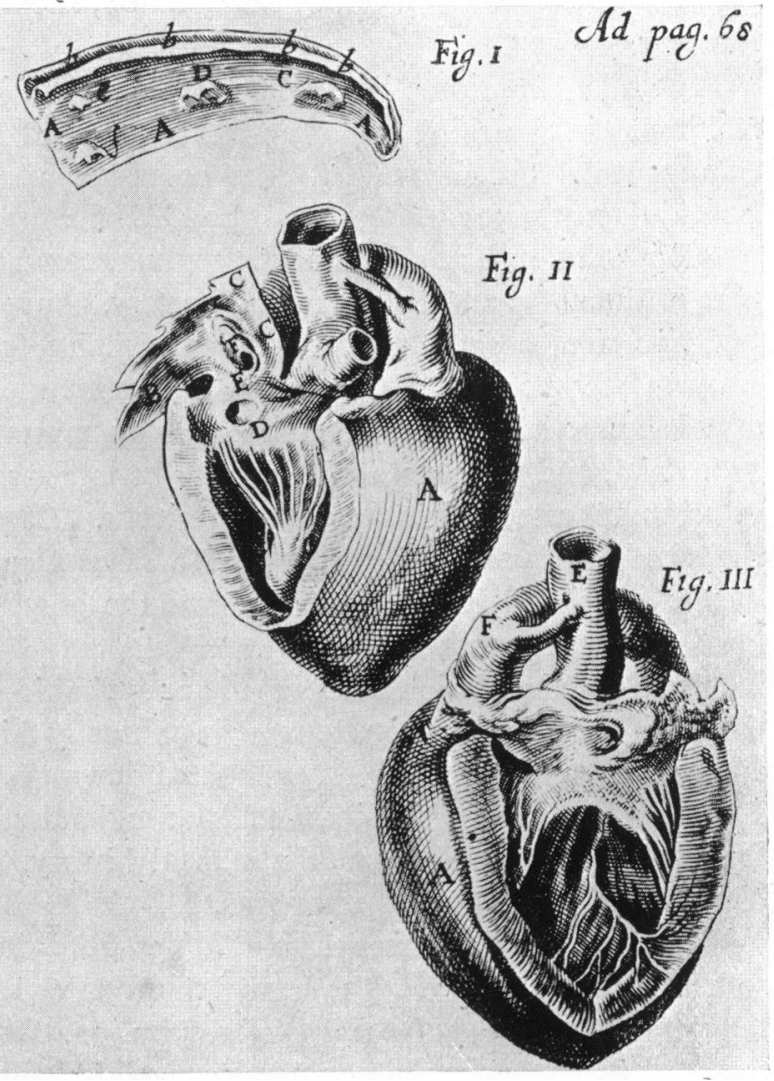

FIG. 7.-Van Horne's edition of Botallo's complete works (1660) contains this illustration inserted by the editor and not included in Botallo's original text. Botallo did not describe the ductus and the structure depicted in van Horne's illustration is anatomically incorrect.

From aorta to pulmonary artery there flows through the ductus a continuous stream of blood, often in great amount, which passes through the lungs to return immediately to the left ventricle and thereby complete a valueless short circuit. The leak from the aorta results in a low diastolic pressure, imposes an added burden on the left ventricle, and by increasing the pressure in the pulmonary artery adds also to the work of the right ventricle. The pulmonary artery dilates throughout its distribution, the lungs become increasingly vascular, and if the leak be sufficiently great, the circulatory phenomena in the periphery come to resemble more and more closely those of aortic regurgitation. Depletion of the general circulation is said to account for the common state of subnutrition and for the child's failure to thrive.

The careful physiological studies of Keys and Friedell (1939), Keys, Friedell, Garland, Madrazo, and Rigler (1940), Eppinger, Burwell, and Gross (1941), and Leeds (1942) have proved most illuminating. It has been demonstrated that the flow through the ductus can be very large, up to 50 per cent or more of the left ventricular output. The right ventricle receives the peripheral venous return which is passed through the lungs to the left side of the heart. The pulmonary artery is therefore filled from two sources. It receives the venous blood on its way to the lungs and also an arterial supply shunted from the aorta via the patent ductus. Consequently the lung vessels handle perhaps 50 per cent more blood than in health, all of which is returned to the left ventricle. The output of the two ventricles is therefore unequal, the left exceeding the right by the volume of blood accepted by the ductus and pulmonary artery.

It is very remarkable that the additional work imposed on the left side of the heart does not result in more serious signs of myocardial insufficiency and a greater degree of ventricular 
hypertrophy. A peripheral arterio-venous fistula of equal size, uniting femoral artery and vein, imposes a greater burden upon both ventricles and leads to a great increase in heart size. The explanation of the difference is probably to be found in the nature of the "venous "side of the fistula. In the case of the patent ductus, constriction of the finer divisions of the pulmonary artery constitutes an area of peripheral resistance which effectively limits the blood flow through the ductus by maintaining a degree of pressure in the pulmonary artery. In the usual peripheral arterio-venous fistula the blood escapes readily into the capacious venous system at low pressure, and against little resistance. This leads to progressive dilatation of the heart and of the entire circulatory bed through which the short-circuited blood flows. It may be suggested that in the presence of a patent ductus arteriosus the finer subdivisions of the pulmonary artery by imposing a degree of peripheral resistance in the lesser circuit effectively protect the left ventricle from overstrain. Hypertrophy of the media of the finer pulmonary arterioles is sometimes demonstrable. Bettinger (1941) believes that hypertrophy of the right ventricle with constriction of the lung arteries are compensatory phenomena, overloading of the pulmonary system being thereby reduced to a minimum. For a discussion of the circulatory dynamics of peripheral arterio-venous fistulæ, which have much in common with the disturbance of the circulation attributable to a patent ductus, reference may be made to the papers of Lewis and Drury (1923), Harrison, Dock, and Holman (1924), and Holman (1940a).

Pathological statistics regarding the size of the patent ductus arteriosus are misleading, as the channel shrinks in a remarkable way after death. At operation it is usually found to be a large vessel, often as wide as the arch of the aorta. In length it is relatively shorter in adults than in children but is usually cylindrical in shape, thus permitting ligation. Gerhardt (1867) has described various types of patent ductus arteriosus: (1) the cylindrical, (2) the funnel-shaped with the apex towards the pulmonary artery, (3) the important window-type which may be better likened to the artificial stoma of a gastro-enterostomy (this is not amenable to surgical ligation), and (4) the aneurysmal form. Keys and Shapiro (1943) collected 10 examples of the fistula-like opening between the pulmonary artery and aorta in their review of 60 fatal cases. Of Jager and Wollenman's (1942) 71 autopsy specimens, 3 obtained from infants were of the window type. So far there is no means of recognizing with certainty the type of ductus likely to be encountered at operation, though angiocardiography may yet provide the help required.

\section{Present InVestigation}

All the patients composing the present series have been personally examined and seen repeatedly during the past four years. A few others have been excluded for various reasons, chiefly the impossibility of following their progress. Two patients seen in hospital some years before the present studies have re-attended and have been included, so that the longest period of observation extends to 14 years (Case 16). The shortest period is 2 months (Case 28).

This series is composed of 28 patients, 15 females, and 13 males-a higher proportion of males than usually found. It is universally agreed that patent ductus arteriosus is more common in the female sex. Keys and Shapiro (1943) in an analysis of causes of death found 14 men and 46 women. Donovan (1943) reporting the cases under the care of Gross verified surgically found 17 males and 33 females. Keys and Violante (1940) observed 6 males and 17 females. Muir and Brown (1932) based their report on 7 males and 13 females. The condition of patent ductus arteriosus is therefore about twice as common in females as in males.

The Age Distribution. The average age for the whole series of 28 is 15 years, the oldest survivor at the present time being now 49 and the youngest 4 years. There is general agreement that patent ductus arteriosus is more frequently met in the first ten years of life. Its 
recognition after 20 or 30 is unusual and in sharp contrast to another and perhaps more common congenital disease-auricular septal defect-which comes under observation as a rule in middle or later adult life. Comparative figures are presented in Table III, which shows the age distribution of two series, one personally observed and the other collected. The 25 examples of auricular septal defect were observed over the four-year period during which the 28 cases of patent ductus arteriosus were studied.

TABLE III

Age Distribution of Patent Ductus Arteriosus and Auricular Septal Defect

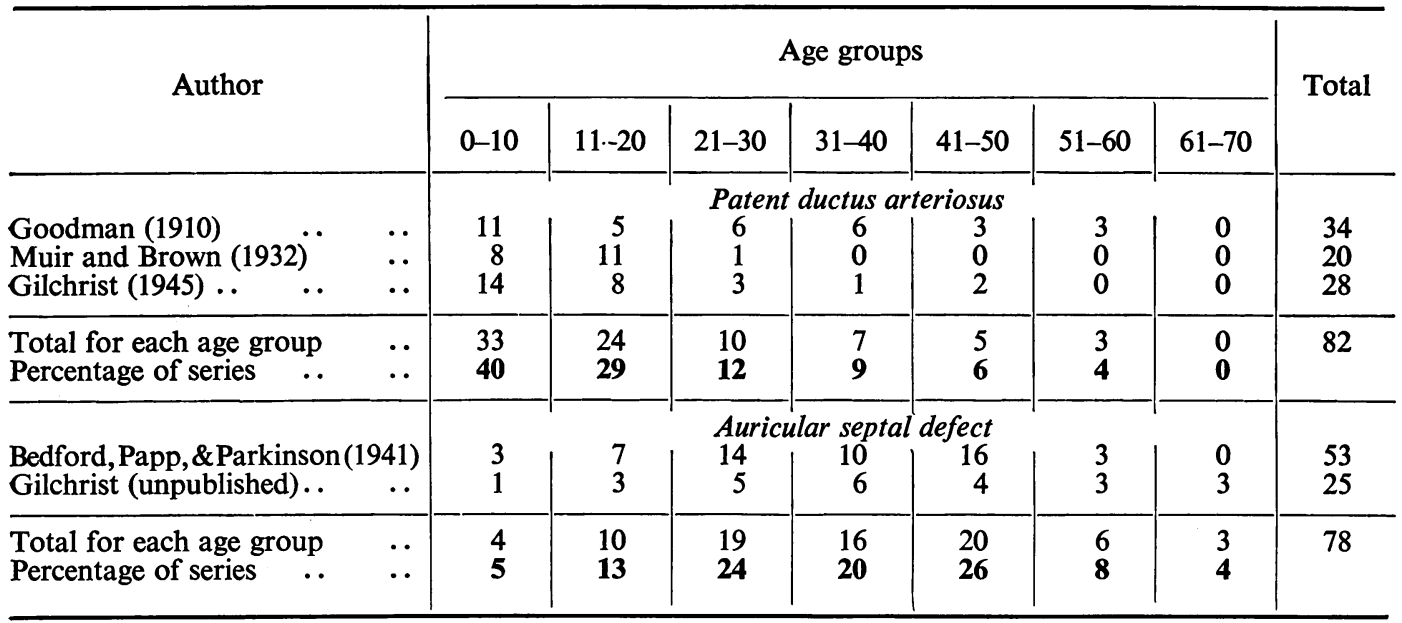

Contrasting the incidence of these two, it is evident that patent ductus arteriosus is recognized at an earlier age than auricular septal defect. Of the former, 70 per cent are recognized before 20; whereas the reverse holds true for the auricular defect, 82 per cent coming under observation after 20 years of age.

There are probably several explanations for this finding. The routine examination of school children permits the ready detection of the relatively simple physical signs of patent ductus arteriosus, whereas auricular septal defect is latent and easily overlooked in youth and produces its ill-effects and more urgent symptoms in later life, when the physical signs are gross, the X-ray picture distinctive, and the diagnosis only then relatively straightforward. That this is not an entirely adequate explanation for the distribution of the ductus cases is proved by the fact that it is extremely difficult, if not impossible, to collect a series of adults with frank signs of uncomplicated patent ductus arteriosus. The problem may be presented from a different angle. Suppose, for instance, that auricular septal defect was a condition easy of recognition in childhood. It is then still logical to assume that patients so affected would continue to present themselves for treatment in the later age groups as they do at present. Patent ductus arteriosus, though recognized in youth, is not a condition which runs a course comparable to auricular septal defect. After the ductus cases pass from the care of the pædiatrician their numbers apparently decrease to such an extent that they are seldom recognized either in the wards or in the post-mortem room.

The scanty number of adults with patent ductus might be attributed to the clinician's failure to recognize the less characteristic signs. A further possibility is that by the time the older patients present themselves for treatment the usual diagnostic features may have altered, diminished in intensity, or even disappeared completely. Well-authenticated cases are on record where experienced observers have failed to detect the characteristic murmur and the diagnosis was only established at autopsy. Duroziez (1862) reported the death of a man, aged 40, in congestive heart failure in whom at autopsy a patent ductus admitting a large pea was found, no murmurs having been heard during life. Foulis (1884) noted in his patient that the murmurs present disappeared twenty-six days before death. Keys and Shapiro (1943) had a patient under observation for ten days in whom at autopsy the ductus was $2 \mathrm{~cm}$. long and $1.5 \mathrm{~cm}$. wide, but no murmurs were heard.

It is therefore evident that, in the presence of congestive heart failure, reliance cannot be placed on the auscultatory signs alone. To do so implies that the diagnosis during the terminal illness may be missed. 
Similarly, the small number of adult cases recorded by the pathologist demands an explanation. White (1926), for instance, could only discover 7 instances of patent ductus arteriosus in patients over the age of one year amongst 5000 consecutive autopsies, and of these 3 were adults. Two possibilities arise. Either pathologists are failing to look for the lesion systematically, or else it may be that as the patients grow older the ductus closes spontaneously and all evidence-clinical and pathologicalof the original defect disappears. That such an event can occur is evident from my Case 22, but it must be exceptional. Otherwise clinicians could hardly fail to have made the observation repeatedly. The problem of the scanty number of adult patients is not yet solved, but there is reason to suppose that it will be simplified if the clinician will put greater trust in the more stable physical signs-the enlarged pulmonary artery and the high pulse pressure-and less in the characteristic murmur, which is apt to disappear when congestive heart failure is present. Similarly, the careful inspection by the pathologist of the region of the aortic isthmus as a routine procedure in every case would do much to simplify the problem of the lack of known examples of patent ductus arteriosus in the adult population.

The 28 patients in this series have been divided into two groups. Group A is a control series of 14 patients in whom for one reason or another surgery was considered unnecessary or undesirable. Group B is composed of 14 patients submitted to surgical ligation. Their progress was observed for varying periods of time before surgery was undertaken, 9 years in one instance, and so far a maximum of 45 months and a minimum of 6 months have followed ductal occlusion.

\section{(A) Control Patients (Cases 15 to 28)}

The 14 patients in this group consist of 9 females, ranging in age from 5 to 34 years, and 5 males of from 6 to 49 years. The average age in this group is 20 years. Certain details are shown in Table IV. Two of the 14 patients have died-Case 23, at 42 of subacute bacterial endarteritis with congestive heart failure, and Case 24, at age 15 of acute poliomyelitis with respiratory paralysis.

Fatal Cases. From a study of reported cases Keys and Shapiro (1943) find that 42 per cent of patent ductus arteriosus deaths are the result of subacute bacterial endarteritis of the pulmonary artery and ductus. There is reason to believe that this infection is even more common. It masquerades under various erroneous diagnoses, mostly with a pulmonary background, for example, miliary tuberculosis, tuberculous pneumonia, sulphonamiderefractory pneumonia, mitral disease with pulmonary infarction, or simply as septicæmia. In Horder's (1940) opinion a number of infected ductus patients find their way to sanatoria and remain undiagnosed to die of septicæmia, anæmia, and congestive failure. Up to 1932 only 23 reported cases of infective endarteritis could be collected (Fischer and Schur, 1932).

The diagnosis is important as surgery promises now at least a 50 per cent rate of recovery, whereas on medical measures the disease is uniformly fatal. No patient with a patent ductus should be allowed to run an unexplained fever for as long as 10 days without blood cultures and radiograms of the lungs for infarcts. Surgical ligation is the only treatment to consider. In Case 23 we decided that the opportunity for ligation had passed, the local infection being so extensive and the prospects so poor that surgery after thirteen months of septicæmia offered no hope of cure. Subacute bacterial infection can occur at any age, though most uncommon in the first decade (Hubbard, Emerson, and Green, 1939) and strikes the apparently symptomless as well as the more handicapped patient without warning. If it is, as statistics would suggest, a leading cause of death in patent ductus arteriosus, it is curious that the general hospitals are not more familiar with it and that it should still be regarded as a rarity in pathological and clinical experience. My personal experience is limited to three cases seen during the past four years.

Case 24 is instructive for another reason. This girl died of an intercurrent infection in another hospital. It was natural that in view of the diagnosis of poliomyelitis the pathologist should devote particular care to the central nervous system. Although the diagnosis of patent ductus arteriosus was 
TABLE IV:

Features of 14 Control Patients (Group A)

\begin{tabular}{|c|c|c|c|c|c|c|c|c|}
\hline \multirow{2}{*}{$\begin{array}{l}\text { Case No., } \\
\text { Sex, and } \\
\text { Age }\end{array}$} & \multirow{2}{*}{ Occupation } & \multirow{2}{*}{$\begin{array}{l}\text { Date of } \\
\text { examina- } \\
\text { tion }\end{array}$} & \multirow{2}{*}{$\begin{array}{l}\text { Physical } \\
\text { capacity }\end{array}$} & \multicolumn{2}{|c|}{ Heart size } & \multicolumn{2}{|c|}{$\begin{array}{c}\text { Blood } \\
\text { pressure }\end{array}$} & \multirow{2}{*}{ Remarks } \\
\hline & & & & m.t.d. & P.A.I. & Syst. & Diast. & \\
\hline 15. m. 45 & $\begin{array}{l}\text { College } \\
\text { lecturer }\end{array}$ & $\begin{array}{l}11 / 3 / 40 \\
21 / 7 / 44\end{array}$ & 2 & $\begin{array}{l}160 \\
185\end{array}$ & $\begin{array}{l}80 \\
89\end{array}$ & $\begin{array}{l}168 \\
180\end{array}$ & $\begin{array}{r}88 \\
105\end{array}$ & $\begin{array}{l}\text { A neurotic man. Highly irregular pulse (Fig. 6). } \\
\text { Slight deterioration in health. }\end{array}$ \\
\hline 16. f. 20 & Housework & $\begin{array}{l}6 / 10 / 30 \\
24 / 3 / 41 \\
27 / 6 / 44\end{array}$ & $\begin{array}{l}2 \\
2 \\
2\end{array}$ & $\begin{array}{l}130 \\
127\end{array}$ & $\overline{64}$ & $\begin{array}{l}110 \\
132 \\
140\end{array}$ & $\begin{array}{l}50 \\
60 \\
72\end{array}$ & $\begin{array}{l}\text { Fatigue. Working as table-maid. } \\
\text { At sixth month of third pregnancy. Good health. } \\
\text { Busy capable housewife and mother of } 3 \text { children. }\end{array}$ \\
\hline 17. f. 5 & At school & $\begin{array}{r}17 / 11 / 41 \\
13 / 12 / 43 \\
26 / 7 / 44\end{array}$ & $\begin{array}{l}2 \\
2 \\
2\end{array}$ & $\frac{95}{98}$ & $\frac{55}{57}$ & $\begin{array}{l}108 \\
110 \\
106\end{array}$ & $\begin{array}{l}68 \\
64 \\
64\end{array}$ & $\begin{array}{l}\text { Fatigue. Pulmonary systolic. } \mathrm{P}_{2}+\cdot{ } \\
\text { Good health. Gibson murmur heard for first time. } \\
\text { Murmur more intense. Thrill now felt. Health good. }\end{array}$ \\
\hline 18. f. 24 & Housework & $\begin{array}{r}1 / 3 / 43 \\
30 / 9 / 44\end{array}$ & 2 & $\begin{array}{l}148 \\
146\end{array}$ & $\begin{array}{l}75 \\
72\end{array}$ & $\begin{array}{l}120 \\
130\end{array}$ & $\begin{array}{l}30 \\
50\end{array}$ & $\begin{array}{l}\text { In last month of sixth pregnancy. } \\
\text { Tired. Six children. More distressed than during } \\
\text { pregnancy. }\end{array}$ \\
\hline 19. f. 5 & At school & $\begin{array}{l}6 / 12 / 43 \\
20 / 9 / 44 \\
\end{array}$ & 1 & $\begin{array}{l}79 \\
85\end{array}$ & $\begin{array}{l}45 \\
46\end{array}$ & $\begin{array}{l}96 \\
86\end{array}$ & $\begin{array}{l}56 \\
42 \\
\end{array}$ & $\begin{array}{l}\text { Small child, retarded development. No symptoms. } \\
\text { Health satisfactory. Heart enlarging. }\end{array}$ \\
\hline 20. m. 4 & At school & $\begin{array}{r}11 / 4 / 42 \\
13 / 10 / 44\end{array}$ & 1 & $\begin{array}{l}108 \\
114\end{array}$ & $\begin{array}{l}53 \\
55\end{array}$ & $\begin{array}{r}95 \\
110\end{array}$ & $\begin{array}{l}45 \\
45\end{array}$ & $\begin{array}{l}\text { Harsh pulmonary systolic. Faint ductal murmur. } \\
\text { I.s.q. }\end{array}$ \\
\hline 21. f. 4 & At school & $\begin{array}{r}25 / 10 / 43 \\
19 / 6 / 44\end{array}$ & 1 & 93 & 52 & $\begin{array}{l}110 \\
110\end{array}$ & $\begin{array}{l}50 \\
45\end{array}$ & $\begin{array}{l}\text { Good health. No symptoms. Definite signs. } \\
\text { I.s.q. }\end{array}$ \\
\hline 22. m. 5 & At school & $\begin{array}{l}20 / 8 / 42 \\
26 / 4 / 44\end{array}$ & $\begin{array}{l}1 \\
1\end{array}$ & $\begin{array}{r}101 \\
85\end{array}$ & $\begin{array}{l}55 \\
54\end{array}$ & $\begin{array}{r}76 \\
108\end{array}$ & $\begin{array}{r}? 40 \\
55\end{array}$ & $\begin{array}{l}\text { Definite signs with Gibson murmur. Ht., } 42 \text { in.; } \\
\text { Wt., } 41 \text { lb. (Fig. 8A). } \\
\text { Murmur absent. Ductus closed. Perfect health. } \\
\text { Ht., } 48 \text { in.; Wt., } 50 \text { lb. (Fig. 8B.) }\end{array}$ \\
\hline 24. f. 14 & At school & $26 / 2 / 42$ & 2 & 111 & 60 & 112 & 54 & $\begin{array}{l}\text { Readily fatigued. Died } 9 / 8 / 42 \text { of acute poliomyelitis } \\
\text { after } 4 \text { days illiness. Pathologist failed to report on } \\
\text { state of ductus, etc. }\end{array}$ \\
\hline $25 . \mathrm{f.} 5$ & At school & $\begin{array}{r}26 / 4 / 44 \\
5 / 7 / 44\end{array}$ & 2 & 92 & 50 & $\begin{array}{r}100 \\
90\end{array}$ & $\begin{array}{r}? 60 \\
62\end{array}$ & $\begin{array}{l}\text { Liable to " faints." Weak Gibson murmur. } \\
\text { Gibson murmur almost inaudible. ? Ductus closing. }\end{array}$ \\
\hline 26. f. 19 & Telephonist & $4 / 5 / 44$ & 1 & 110 & 70 & 136 & 76 & Fatigue and anxiety. A neurotic girl. \\
\hline 27. m. 37 & Fisherman & $9 / 8 / 44$ & 3 & 118 & 85 & 140 & 72 & $\begin{array}{l}\text { Exertional pain and ready fatigue. Mildly neurotic } \\
\text { since discharge from Royal Navy four months ago } \\
\text { after } 3 \text { years on active service. Slight deterioration } \\
\text { in physical capacity. }\end{array}$ \\
\hline 28. m. 24 & Bus driver & $26 / 7 / 44$ & 2 & 123 & 80 & 118 & 46 & $\begin{array}{l}\text { Slight dyspnœa and fatigue all his life. In semi- } \\
\text { recumbent position a distant, slow Gibson murmur } \\
\text { detected in third left space. Able for work. Since } \\
\text { discharged from Army after } 2 \text { years' service a little } \\
\text { neurotic. }\end{array}$ \\
\hline
\end{tabular}

One Case of Subacute Bacterial Endarteritis

\begin{tabular}{l|l|l|l|l|l|l|} 
23. f. 42 & Schoolteacher & $31 / 3 / 42$ & 5 & Enlarged & - & $\begin{array}{c}\text { Died } 17 / 4 / 42 \text { after a year's illness. Multiple peri- } \\
\text { pheral and pulmonary infarcts, congestive heart } \\
\text { failure, and exhausted state did not justify recom- } \\
\text { mendation for surgery. }\end{array}$ \\
\hline
\end{tabular}

The age stated is that at the time of the first examination.

The physical capacity of each patient has been assessed according to a numerical scale at the corresponding date of examination. Grade 1, no limitation of physical activity; 2 , slight limitation and 3 , moderate limitation on heavier exertion; 4 , ordinary activity causes distress, often with a trace of odema at night; 5 , mild congestive heart failure; 6 , advanced congestive heart failure. Slight deterioration was detected only in three patients-Cases 15,18 , and 27.

Heart size is recorded as the maximum transverse diameter (m.t.d.) in mm. in the teleradiogram. The pulmonary artery index (P.A.I.) is employed as a measure in mm. of the size of the pulmonary artery (Evans, 1943)

The blood pressure figures are the lowest of several readings recorded on the date mentioned.

made beyond doubt clinically and radiologically by at least three independent observers, the pathologist omitted to look for the ductus and made no reference to it in his report. It is certain that many autopsies fail to disclose the patent ductus because of the habit of removing the heart by severing the great vessels proximal to the aortic isthmus. As long as these crude methods continue, so long will pathological help in solving the problem of prognosis remain unavailing. The aortic isthmus is the most neglected region in cardiovascular pathology. Lack of numbers in pathological statistics may well be accounted for by a failure to seek and record the lesion in adults. The attention of the pathologist directed to the region of the ductus in every case of obscure fever or of congestive failure in adults, whether the physician suspects such possibilities or not, will prove of inestimable help in the solution of the problem of prognosis in patent ductus arteriosus.

Progress of Survivors. From a consideration of the ease with which symptoms are induced it can be said that no physical deterioration has been observed, nor does their history 
suggest its development in the years before coming under our observation, in Cases 16, 17, $19,20,21,25,26$, and 28 - that is, in 8 of the 12 remaining patients. The capabilities of some of these patients in relation to their age and heart size are worthy of note.

A married woman now aged 34, observed with particular attention throughout her last pregnancy and labour which she accomplished without distress, is the mother of three children. She is a busy housewife, able for all her work and shows no evidence of increasing cardiac enlargement or of physical deterioration (Case 16). Similarly, Case 28, a soldier aged 24, discharged from the army after 18 months' service, is able for his work as a bus driver. Cases $17,19,20,21,22$, and 25 , are children, who though perhaps a trifle retarded in physical development are in reasonably good condition, fit for school, and up to date have shown no deterioration in the year or two during which they have been under observation.

On the other hand, Cases 15, 18, and 27 have deteriorated slightly. Case 15 is now aged 49 , a neurotic subject, but his response to effort is genuinely impaired, his heart is showing evidence of increasing left ventricular hypertrophy, and he has a highly irregular pulse (Fig. 6). Case 18, a married woman of 26 , has had six children, all alive and well, with no unusual difficulties in pregnancy or labour. Recently her reserves have begun to diminish and in her physical capacity there is slight deterioration. Similarly, Case 27, a fisherman, aged 37, discharged after three years' service with the Royal Navy, now finds his work more exhausting but keeps fit for duty: he shows a slight limitation of physical capacity. No enlargement of the heart is demonstrable in either Case 18 or 27.

In the group as a whole a distinct neurosis was present in four patients. Most advanced and most incapacitating in Case 15, it was also a handicap in Case 26, being based originally on an incorrect diagnosis, and to a less extent in Cases 27 and 28, both of whom had been discharged from the services on account of the accidental discovery of physical signs. Brown (1932) noted neurotic tendencies in 2 of his 20 patients.

Spontaneous Closure of the Ductus. One remarkable patient (Case 22) in this group demands special emphasis. This boy at the age of 5 had an enlarged heart with a whirling Gibson murmur at the usual site. By the age of six and a half the murmur had disappeared, the heart had returned to normal, and the boy had grown and developed out of all recognition. Fig. 8, A and B, make a striking contrast. Spontaneous closure in an active, growing boy has seldom been observed, and so far as I have been able to discover, has not previously been substantiated by radiological proof.

Balfour's (1898) report is not very convincing. He describes how after a lapse of 15 years a murmur originally attributed to a patent ductus had disappeared. The patient was " a young lady . . . there was neither duskiness of complexion nor any murmur left. Evidently the ductus arteriosus had completely closed as it is occasionally known to do even late in life." Williams (1909) mentions a child "with a loud and prolonged murmur of roaring character continuous through the whole cycle. After $2 \frac{1}{2}$ years it had been replaced by a faint systolic bruit." The conclusion that gradual obliteration of the ductus arteriosus had taken place, or was in progress, seems amply justified from the scanty facts. Jacobi (1914) makes the interesting statement that, after observing a child once or twice a year from infancy, the ductus closed about the age of 9 or 10, "the murmur getting less and less marked until it finally disappeared." Keys and Shapiro (1943) refer briefly to two remarkable patients under their observation, who have recently shown evidence of spontaneous closure and disappearance of all signs of any lesion.

Spontaneous closure of the ductus can occur, presumably at any age, though to judge from clinical experience and the scanty reports, it must be very rare. Presumably the process is more likely to occur when the ductus is small, as in childhood, and before dilatation of the pulmonary artery has developed to a substantial degree and before degenerative atheromatous changes, with loss of elasticity of the vessel walls, have occurred. It is evidently a gradual process. It seems possible that closure might have been excited by the alterations in intra-pulmonary pressure, the accompaniment of the severe attack of whooping cough from which this boy suffered. On the other hand, several other children in this series have suffered from whooping cough without any change in the character of their physical signs. Whatever the mechanism, the fact remains that spontaneous closure of the ductus, up to the age of 10 or even older, is a possibility to be considered. 


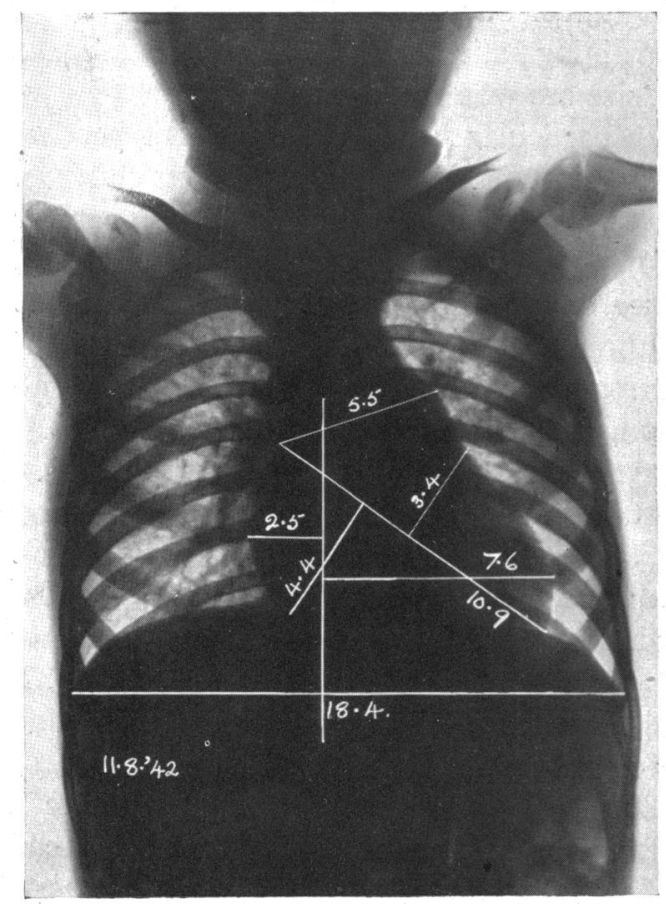

A

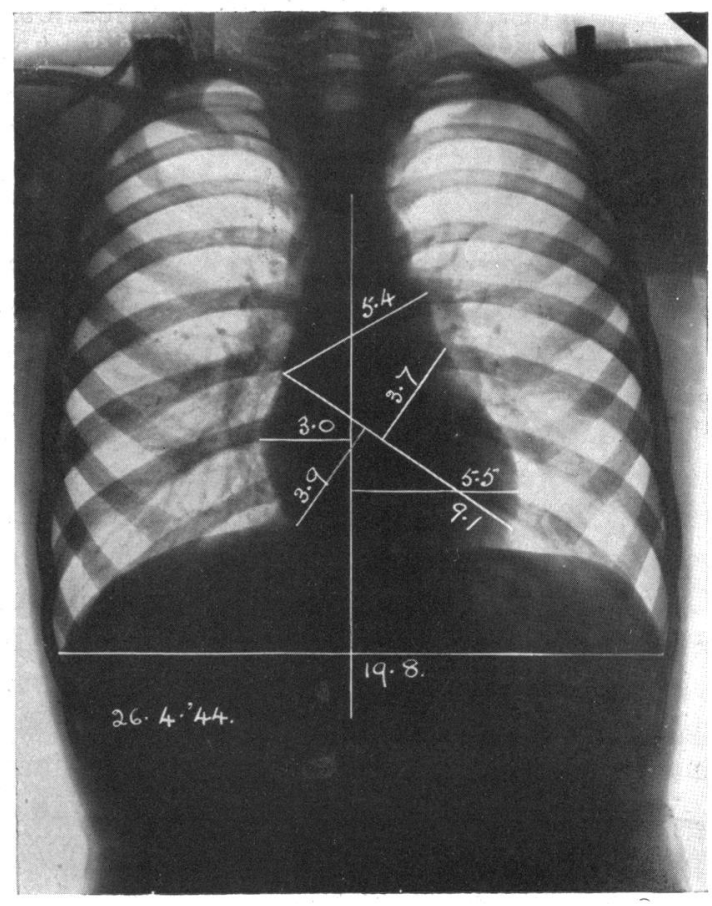

B

FIG. 8.-Spontaneous closure of the ductus between the age of 5 and $6 \frac{1}{2}$ years. Case 22. (A) Radiogram of August 1942 shows considerable cardiac enlargement. The m.t.d. is $10 \cdot 1 \mathrm{~cm}$. and P.A.I. $5 \cdot 5 \mathrm{~cm}$., with distinct prominence of pulmonary arc and increased vascular markings, particularly in the upper and mid-zones of both lungs. The physical signs of patent ductus were well-marked. (B) The same child in April 1944. No physical signs of P.D.A. Gibson murmur no longer heard. Note striking decrease in size of heart, affecting chiefly the left ventricle, the clear lung fields and the growth of the thorax. The m.t.d. is now $8.5 \mathrm{~cm}$. as compared with $10 \cdot 1 \mathrm{~cm}$. 20 months previously.

Summary. To summarize the essential features of this group, observation of the 14 patients has shown no deterioration in 8 , slight deterioration in 3 , death in 2 (one from subacute bacterial endarteritis and one from intercurrent infection), and recovery (spontaneous closure of the ductus) in $1-$ a boy of $6 \frac{1}{2}$ years. It is noteworthy that the majority lead normal active lives. Two women have married and have borne families without cardiac incapacity. From such facts as these it might be argued that surgical intervention has little to offer and that, reaching early adult life, many patients keep remarkably free of incapacitating symptoms, and are capable of leading useful lives.

\section{The Objects of Surgical Ligation}

Few will quarrel with the surgeon's intentions. He seeks to restore the integrity of the circulatory system embarrassed by an arterio-venous fistula of a peculiar type. Holman (1940a) has pointed out how in peripheral arterio-venous fistulæ abolition of the leak results in a prompt reversal of the circulatory changes, a permanent elevation of the diastolic pressure due to elimination of the focus of low peripheral resistance being one of the most notable findings. On this there follows a gradual reduction in the size of the heart and of the vessels to and from the previous site of the fistula. This is attributed to a reduction in the volume of blood traversing that part of the circulatory bed common to the primary and secondary circuits.

Applying these results to patients in whom the patent ductus arteriosus has been ligated, it is reasonable to expect a reduction in the size of the heart, chiefly on the left side, and of 
the pulmonary artery and all its branches throughout its distribution. By sealing the leak the work of the heart is reduced and circulatory efficiency correspondingly improved. In contrast to many other pathological states, therapy does not merely arrest the disease: it activates a reversible process as a result of which myocardial tone is fully restored. There is therefore every reason to suppose that ductal occlusion will prevent the development of congestive heart failure to which these people are believed to be particularly liable. The harmful effects of persistent patency of the ductus are bodily under-development and malnutrition, with a low-grade circulatory incapacity leading to congestive heart failure. Surgery can correct these tendencies.

Sufficient time has not yet elapsed to judge of the influence of surgical ligation on the prevention of bacterial endarteritis of the ductus or pulmonary artery. There is every reason to suppose that the risk of this most serious complication will be greatly reduced in the future. Our present conception of the nature of this disease is based on the belief that the infection develops at the site of intimal damage. Exposed to a high pressure jet from the ductus, and with swirling blood currents constantly impinging on its walls, the pulmonary artery is submitted to excessive strain which over a period of years leads to intimal thickening, to cholesterol deposition, and ultimately to the formation of the typical atheromatous plaques. These occur at the orifices of the ductus but are most marked on the wall of the pulmonary artery, lying immediately opposite the orifice of the ductus. It is at this site that the infection becomes localized and vegetations most profuse (Fig. 9). It is reasonable to suppose that ligation of the ductus in early life will prevent the local degenerative vascular changes that predispose to bacterial endarteritis.

On the other hand, it has been suggested that at each end, adjoining the aorta and pulmonary artery, the remnants of the ligated ductus will form crypts which might afford a lodging for a blood infection. Only a few autopsies have been made after successful ligation of the ductus so that conclusive evidence of the nature of the obliterative process at the former ductal orifices is not available, but Tubbs (1944) in one patient (his Case 9) found four months after surgical occlusion that the ends of the ductus, which itself had been completely obliterated, were represented by no more than shallow depressions, with smooth floors devoid of thrombi. It would seem that the crypts produced by ligation of the ductus are unlikely to persist. Hence the risk of infection should be greatly reduced.

The rationale of ligation in the presence of an acute or subacute endarteritis of the ductus arteriosus and pulmonary artery is a difficult problem. It has been discussed by Touroff (1942a) and Tubbs (1944), the consensus of opinion being that a number of factors must play a part in the eradication of the disease by this means. Boldero and Bedford (1924) suggested that the rarity of bacterial endocarditis on the right side of the heart might be accounted for by the reduced oxygen content of the venous blood. Ligation of the infected ductus will deprive the local infection of arterial blood and reduce the wear and tear to which the pulmonary artery and its contained vegetations are exposed. Touroff (1942a) emphasizes the importance of the cessation of the forceful blood-flow through the ductus whereby fragmentation of the infected clot is greatly reduced. As a result of ligation he believes that the lung capillaries, now less dilated and fed by a blood-stream at a reduced pressure and volume, are able to filter off the few emboli that are formed. The rapidity with which the blood infection comes under control after ligation is very remarkable. For example, in one of the patients (his Case 6) reported by Tubbs (1944) 130 colonies of a Strept. viridans per c.c. were obtained before operation, whereas 37 minutes after ligation the blood grew 26 colonies, four hours after 8 colonies, seven hours after 5 colonies, and next morning only 1 colony per c.c. Presumably the lungs filter off the organisms and the vegetations heal by organization of the clot.

The ligation of the ductus was first suggested by Munro (1907). The first attempt by Graybiel and Strieder (1938) failed for technical reasons, and the patient died a few days later. It remained for Robert Gross of Boston to devise and perfect the trans-pleural approach, the 

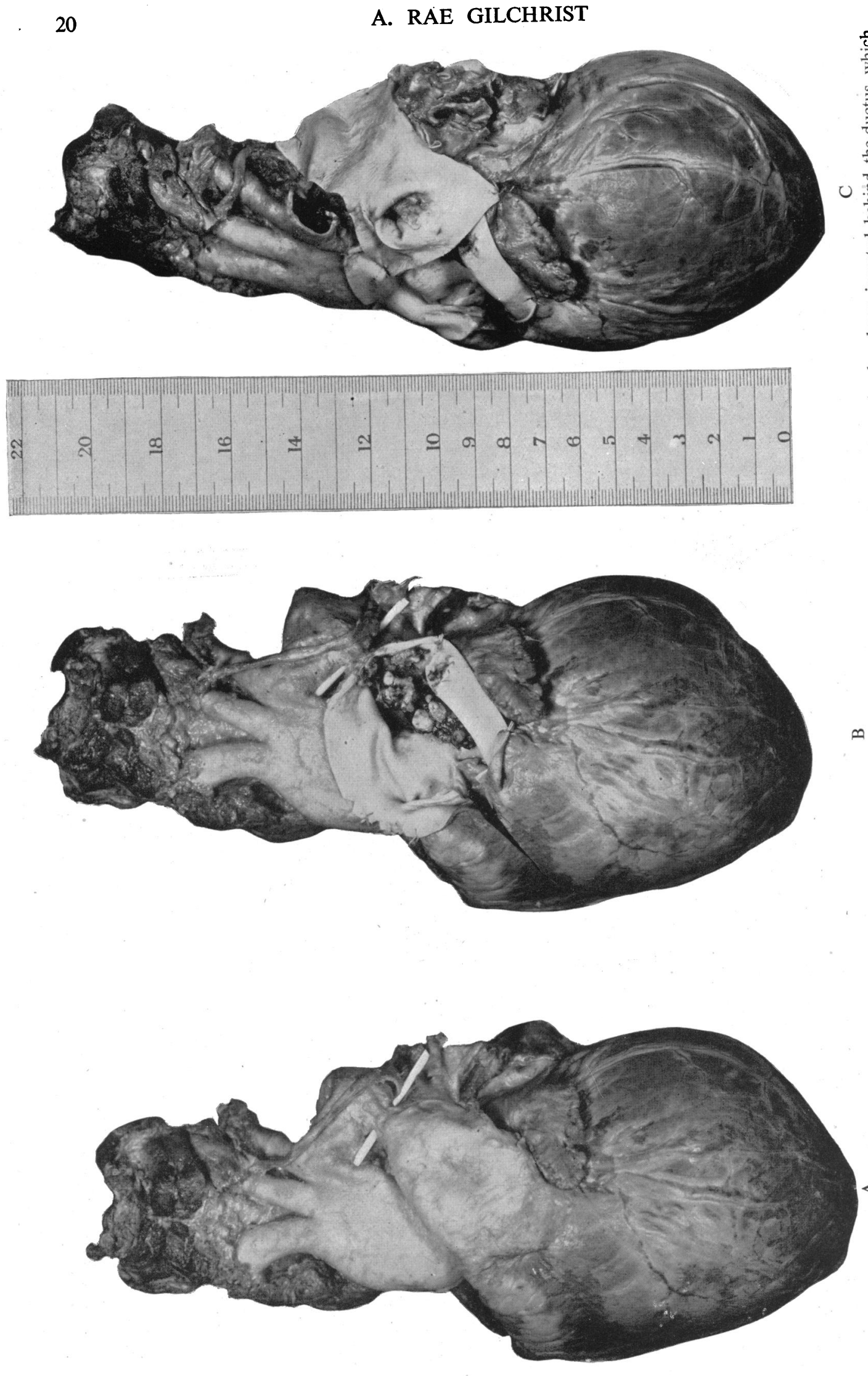

둥후ㅇㅝㅗ월

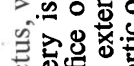

을

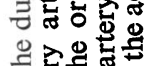

○

记

월형

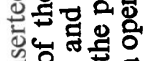

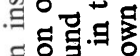

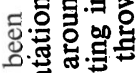

帚巻응

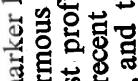

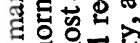

<它军焉

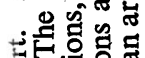

可

楁

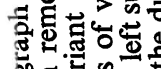

政

눙

这要

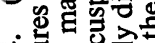

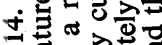

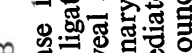

ช8

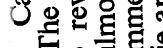

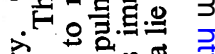

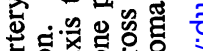

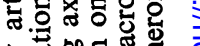

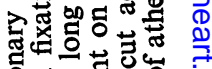

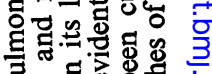

들.

․ㅗㅀ월

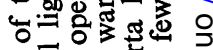

․ㅠ

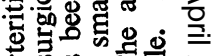

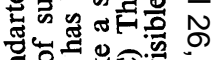

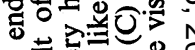

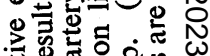

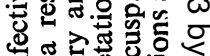

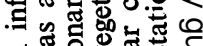

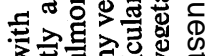

क्ष

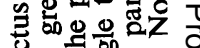

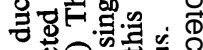
苞色《。

过 में

!.

岀 흫 
first successful ligation being reported by Gross and Hubbard (1939). The details of the Gross technique $(1939 a, 1939 b)$ have been modified slightly, Touroff $(1942 a)$ in particular emphasizing the great advantages of subadventitial dissection on the arch of the aorta. Harrington (1943) recommends a posterro-lateral approach to the mediastinum in preference to the antero-lateral used by the majority of thoracic surgeons. Since 1939 the brilliant achievement of Gross has been repeated in various parts of the world. Shapiro and Keys (1943), with the cooperation of surgeons throughout the United States and Canada, were able to collect 140 cases. Of 107 non-infected cases ligation was completely successful in 81 , and 9 patients died at or shortly after operation. Of 33 examples of subacute bacterial endarteritis, surgery was completely successful in 20 , and 5 patients died at operation.

\section{(B) Patients submitted to Surgical Ligation (Cases 1 to 14 )}

The 14 patients in this group consist of 6 females, ranging in age from 5 to 28 years, and 8 males of from 4 to 19 years. The average age of this group is 13 years. Four deaths must be recorded, two patients dying from subacute bacterial endarteritis, on which account surgery was undertaken (Cases 1 and 14), and two, non-infected patients, dying in the period after operation. One died from hæmorrhage from a torn ductus (Case 2); the other's death was attributed to a deep-seated mediastinal infection (Case 12).

The Infected Ductus. The work of Touroff $(1940,1942,1943)$ and Tubbs (1944) indicates without a doubt the justification, indeed the absolute necessity, for recommending ligation of the infected ductus. The condition carries with it all the gravity of an ulcerative endocarditis. The clinical diagnosis is based on evidence of septicæmia, local signs of a patent ductus, and a patchy consolidation through the lungs, advancing and subsiding as fresh emboli are shed from the vegetations in the ductus or pulmonary artery. From even a limited experience of these patients I should like to suggest that a characteristic X-ray picture exists from which the physician or radiologist may make the diagnosis with confidence (Fig. 10). Absence of the fully-developed radiological appearances does not necessarily exclude the diagnosis but the chest films, revealing prominence of the pulmonary artery, progressive cardiac enlargement, and patchy consolidation throughout the lung fields, advancing here and subsiding there, must make a unique combination on which the diagnosis can be made. So far as the heart itself is concerned, the noteworthy finding is the rapid development of cardiac enlargement affecting chiefly the left ventricle, and increasing dilatation of the pulmonary artery. Other causes for enlargement of the pulmonary artery, such as auricular septal defect, are accompanied by right ventricular hypertrophy and are seldom if ever complicated by a local subacute infection. Great enlargement of the heart in the presence of a patent ductus is always suggestive of a bacterial endarteritis. The successive X-rays recorded at intervals of some weeks and reproduced in Fig. 10, are regarded as the characteristic sequence on which a diagnosis of subacute bacterial endarteritis of the pulmonary artery and patent ductus might be based. Similar X-ray findings were noted in Case 1 and are also evident in the illustrations of one of Touroff's (1943) patients (his Fig. 1, 3, and 6, Case 7). This radiological picture will not be found invariably. Indeed, surgical measures should be undertaken before multiple pulmonary infarcts exhaust the patient, increase the hazard, and complicate the approach to the ductus. Similarly, the chances of success are greater, the less dilated the heart. The accurate interpretation of the radiological findings should reduce the frequency with which the clinical diagnosis of an infected ductus is missed.

The first successful ligation of an infected ductus was done in December 1939 (Bourne and Tubbs, 1941). Since then Tubbs (1944) has reported recovery in 6 of 9 infected cases. Shapiro and Keys (1943) were able to collect the results obtained in 33 patients, including the 12 reported by Touroff (1943), of whom 10 survived operation and 7 recovered from the infection. Recovery was complete in 20 of the 33 patients. Blood cultures became sterile, often with surprising rapidity (Touroff, 1942c, Tubbs, 1944), the general condition improved 
A
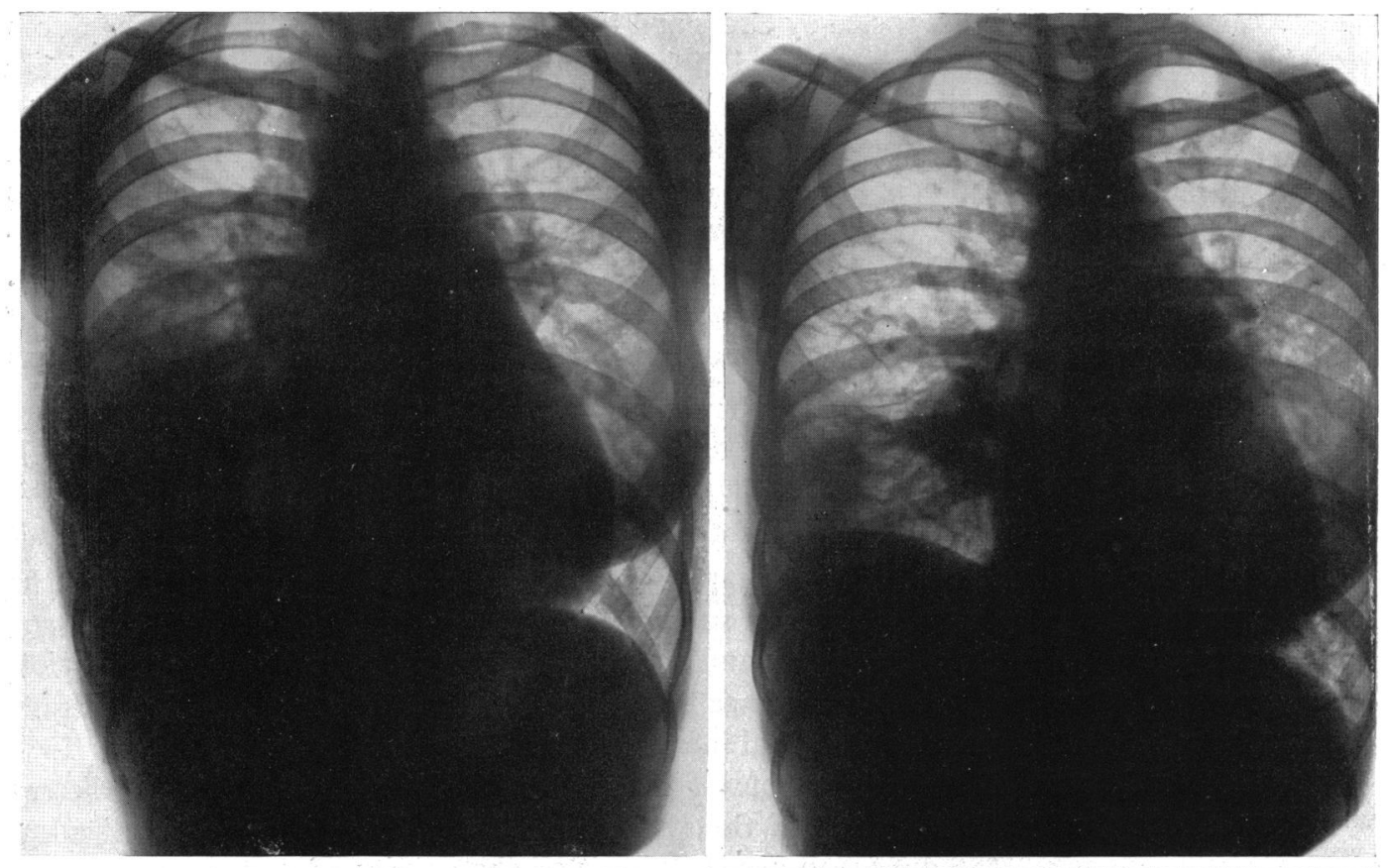

$\underline{0}$
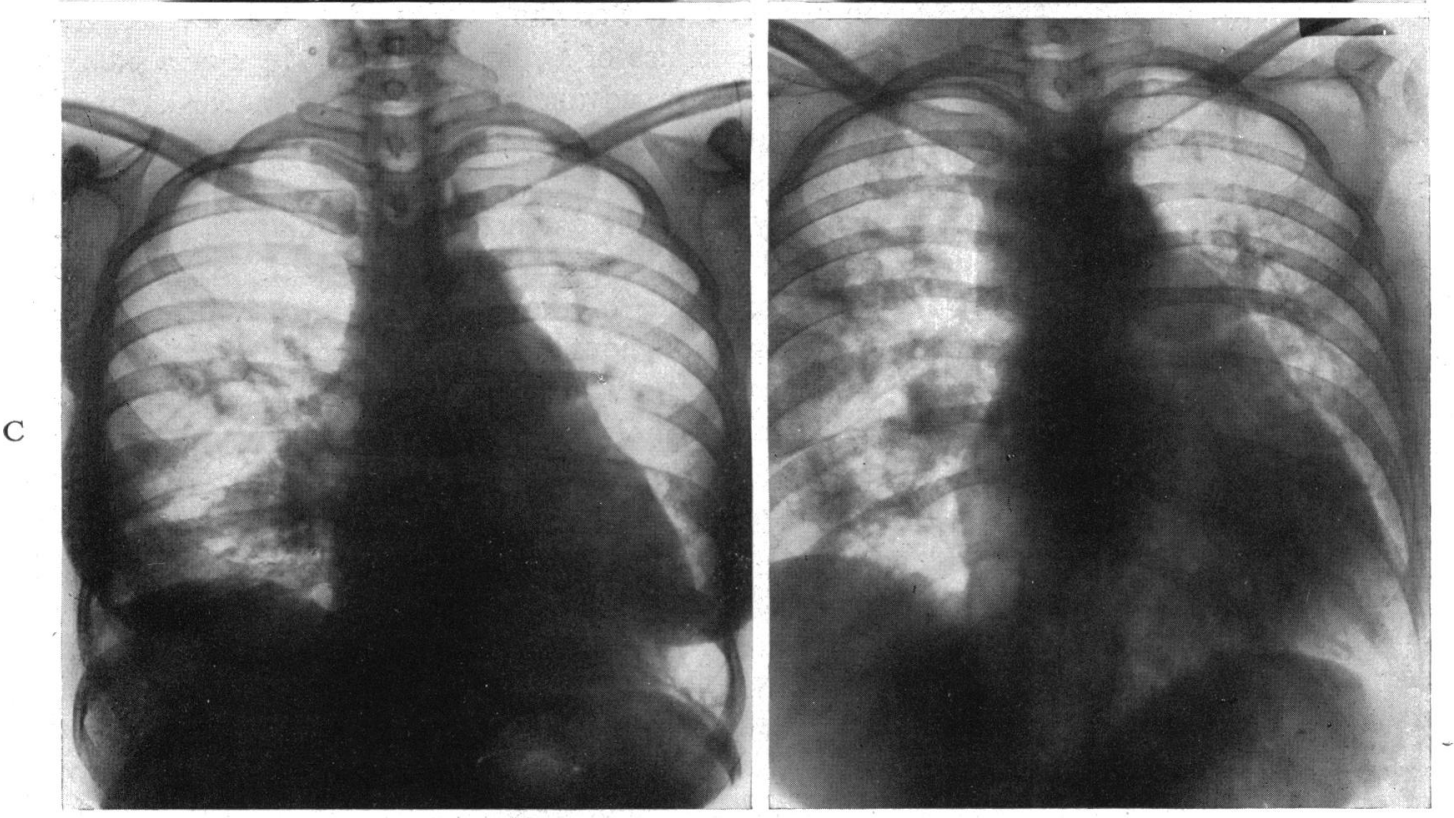

Fig. 10.-Radiograms in bacterial endarteritis. Case 14. (A) Teleradiogram 18/1/44. Enlarged heart, prominent pulmonary arc, P.A.I., $8.4 \mathrm{~cm}$. Consolidation of varying intensity at right base. Increased vascularity of lungs. (B) Teleradiogram $1 / 3 / 44$. Heart a little larger. P.A.I., $8 \cdot 7 \mathrm{~cm}$. Consolidation resolving at right base, a little now at left base. (C) Teleradiogram 11/4/44. Heart larger. P.A.I., $9 \cdot 4 \mathrm{~cm}$. Extension of patchy dullness through mid and outer zones of each lung. (D) Portable film 22/5/44. Extreme cardiac enlargement. P.A.I., $10 \cdot 0 \mathrm{~cm}$. Scattered patchy consolidation through both lung fields.

It is suggested that the progressive enlargement of the heart, with increasing dilatation of the pulmonary arc (P.A.I., rising from 8.4 to $10.0 \mathrm{~cm}$. in 4 months) and the scattered consolidation-advancing here and subsiding there-make up a radiological sequence on which the diagnosis of an infected ductus and pulmonary artery may be made with confidence. For autopsy control, see Fig. 9. 
remarkably, and there is no doubt that the majority have been restored to perfect health, though admittedly the progress of a small number has only been observed for a period of months. Tubbs' (1944) first patient is alive and well $4 \frac{1}{2}$ years after operation.

Fatal Cases. Success did not attend our efforts in Cases 1 and 14. In both patients the infection had run a prolonged course and both were in bad condition when surgery was undertaken. The administration of sulphonamides and penicillin before operation was a waste of valuable time. Complete cure has been brought about by surgery alone (Touroff, 1943, Tubbs, 1944): sulphonamides are unnecessary.

The two other fatal cases remain to be discussed. Case 2, a boy of 5, died from hæmorrhage after a second attempt to ligate the ductus. The first ligation performed in October 1940 was followed by a recanalization of the channel with a return of signs and symptoms after temporary improvement. Fig. 11 depicts the course of the blood pressure findings. Shapiro and Keys

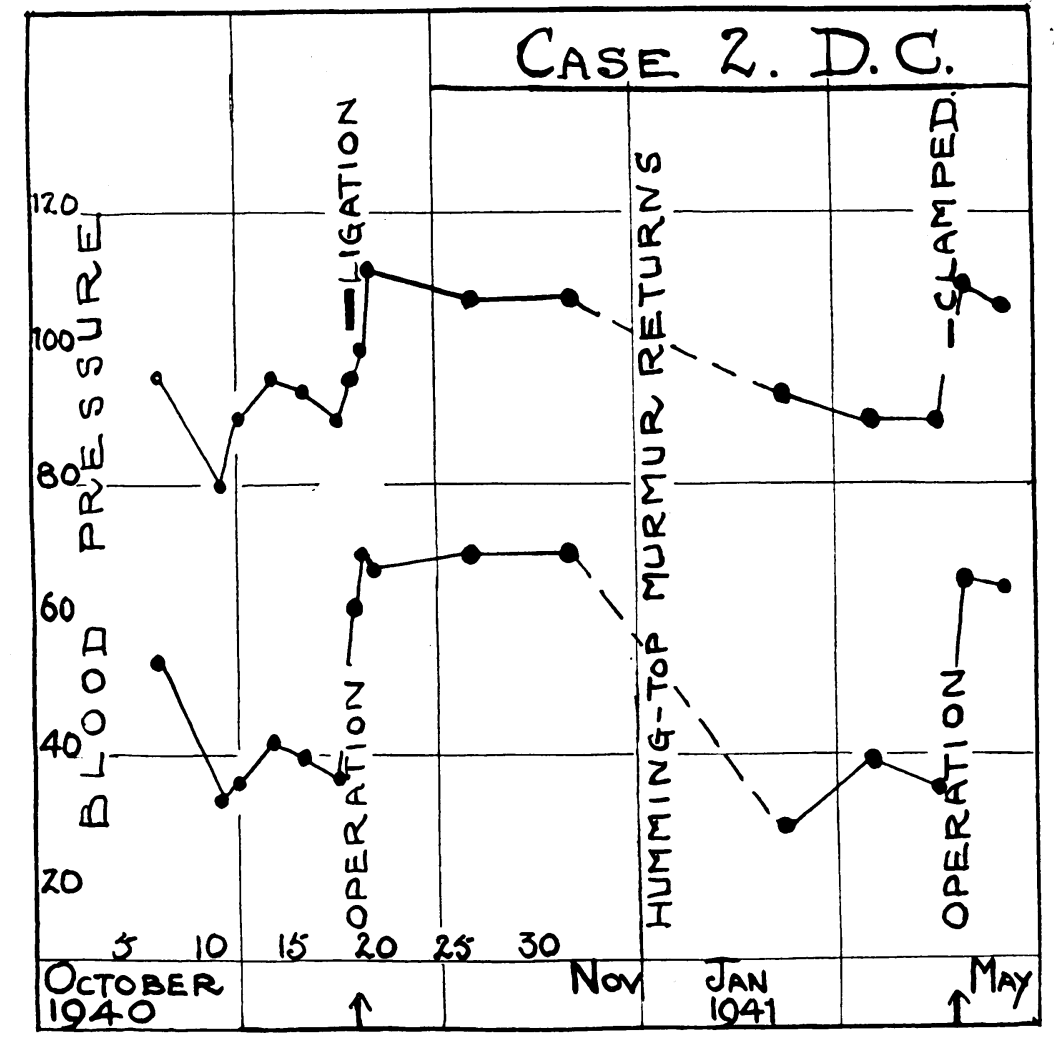

Fig. 11.-Course of the blood pressure in Case 2, a boy aged $4 \frac{1}{2}$. The ductus was ligated on 19/10/40. The channel recanalized, the physical signs returned, and the diastolic pressure fell. A second ligation was done on $26 / 4 / 41$.

(1943) collected the results of 107 ligations report rupture of the ductus at operation in 6. Bleeding can be profuse and exsanguinating and death has occurred on the table. The ductus often belies its appearance. Dilated, friable, and adherent in its postero-medial aspects, it is best regarded as a very fragile structure, tearing readily. Its dissection demands the greatest patience and forbearance, but Touroff's (1942b) new technique of subadventitial dissection on the under surface of the aortic arch should reduce greatly the operative dangers, facilitate ligation, and shorten the surgical procedure as a whole.

In Case 12 the fatal issue was attributed, in the absence of an autopsy, to a deep-seated mediastinal infection. This child's death, one month after a successful ligation, was a great discouragement and casts a shadow over the whole series. It may be that the necessary 
disturbance of the glands and lymphatics at the root of the lung opened a pathway of infection leading from the pulmonary airways to the mediastinal tissues. As a routine procedure dusting with sterile sulphathiazole before closure of the mediastinal pleura might reduce the risk of infection at this site.

Progress of Survivors. The remaining cases-10 in number-have done reasonably well. Progress may be assessed in various ways, of which not the least important is the general clinical impression based on the patient's physical state, sense of well-being, freedom from symptoms, and capacity for exercise, supplemented in the case of a child by the opinion of the mother, or of the patient himself. With such a background a general clinical assessment has been made for each patient. The result after operation in the 10 survivors may be classified as follows.

(1) Excellent: Case 5 (24 months).

(2) Good: Cases 3 (45 months), 8 (7 months), 9 (7 months), 10 (6 months), 13 (6 months).

(3) Fair: Cases 4 (36 months), 7 (7 months), 11 (6 months).

(4) Poor-i.s.q.: Case 6 (9 months).

The times in brackets indicate the period since operation, during which it has been possible to assess each patient's progress. A conservative attitude has been adopted, in that in the case of the children sufficient interval has not elapsed to allow of full correction of their debilitated or subnutritional state, with the result that the present review tends perhaps to minimize the benefits, which ought to become more obvious with the passage of time.

Various measurements, such as height and weight in the case of children; and records of heart size (including measurements of the pulmonary arc) and comparative readings of diastolic blood pressure, are of value in assessing progress. In this connection by far the most spectacular result has been obtained in Case 5, a boy aged 13, whose ductus was ligated on $28 / 7 / 42$. In the succeeding two years this debilitated youth has improved out of all recognition, having gained $43 \mathrm{lb}$. in weight and 8 inches in height. Liable to occasional œdema of the feet and ankles before operation, this boy has been fully restored to perfect health. As a measure of physical fitness, he covered 7 miles in an hour on foot in July 1944.

The change in the size of his heart is illustrated by the successive radiograms reproduced in Fig. 12. While the heart size in relation to the thorax is distinctly less in the last X-ray of the series, yet the cardiac area is actually a trifle larger. Successive transverse diameters of the heart amount to 112,114 , and $114 \mathrm{~mm}$. The corresponding transverse diameters of the thorax measure respectively 225,248 , and $256 \mathrm{~mm}$. It would therefore appear that in the rapidly growing child the heart size remains stationary while the body grows until ultimately each becomes adapted to the other. As a rough and ready record of the degree of distension of the pulmonary artery, Evans (1943) has employed a measurement of the distance between the junction of the superior vena cava with the right auricle and the summit of the pulmonary arc, as demonstrated in the frontal view of the chest. For comparative purposes in the one subject this measurement, known as the pulmonary artery index (P.A.I.), is a useful guide to variations in the size of the vessel. It is interesting to have proof of the shrinkage of the pulmonary arc in the successive X-rays of this patient, the pulmonary index falling from $73 \mathrm{~mm}$. before ligation of the ductus to $59 \mathrm{~mm}$. 2 years later, and this despite a considerable growth of the chest with but little corresponding gain in heart size. Along with the decreased distension of the main trunk of the pulmonary artery, the final teleradiogram reveals a great reduction in the vascularity of the lungs. Fig. 13 depicts the effect of ligation on this patient's blood pressure. No one could fail to be impressed with the phenomenal progress which this boy has made. Surgery has brought a cardiac cripple to full working capacity and endowed him with a new freedom.

Less spectacular results have been obtained in the second group, whose progress may be classified as "good." Case 3 had a surgical ligation done on 23/1/41. His immediate progress was retarded by a massive collapse of the left lung and a copious blood-stained 


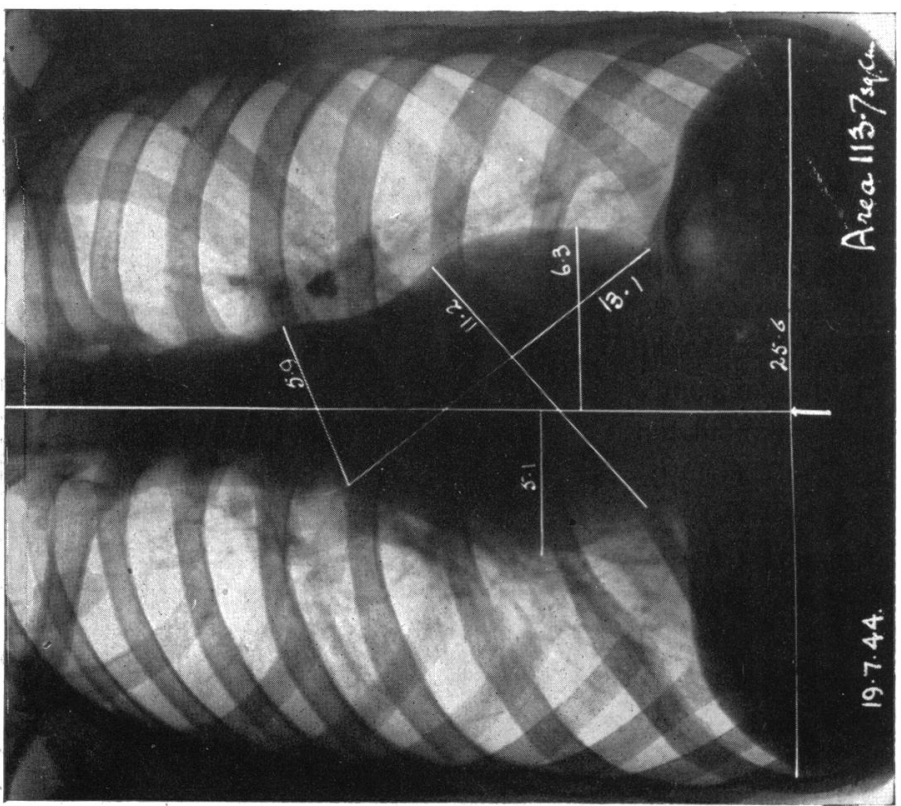

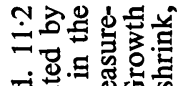
ช̛. घี

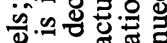

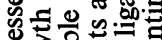
$>3$.

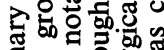

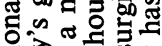
है. के

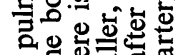

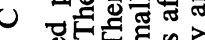

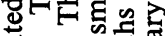
超 政它

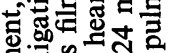

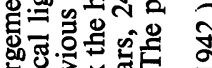
然. ฮี

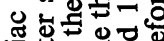

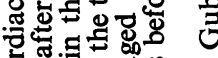
ฮึ.

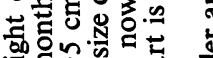

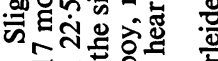

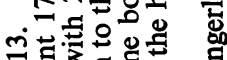

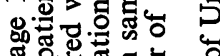
क क

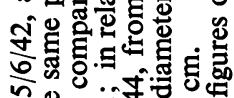

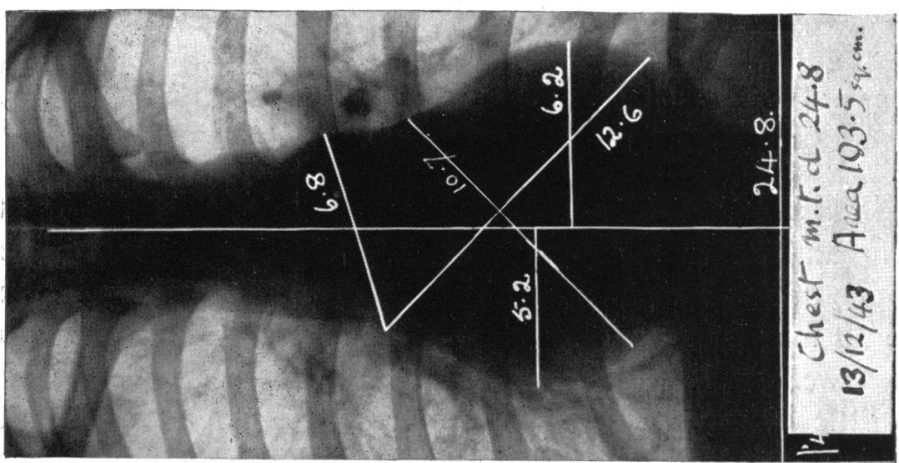

m

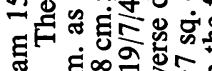

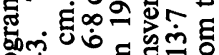

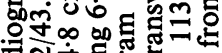

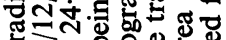
월. ㄴ.

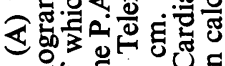

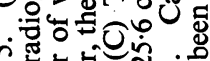

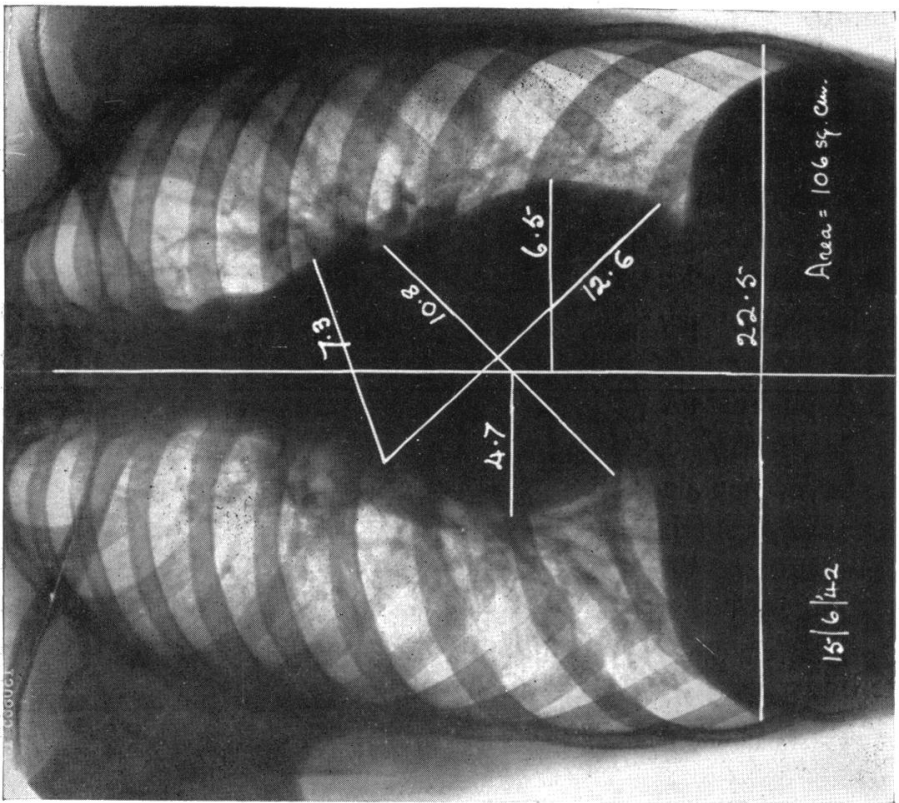

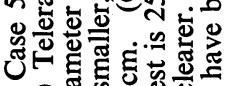

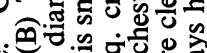
. क 屯

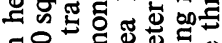

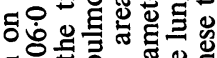

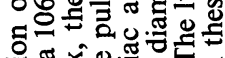

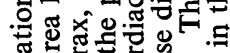

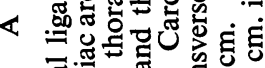

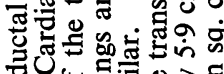

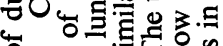

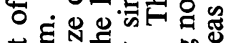
约数

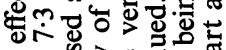

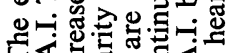
|

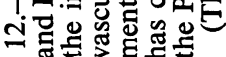
岀 


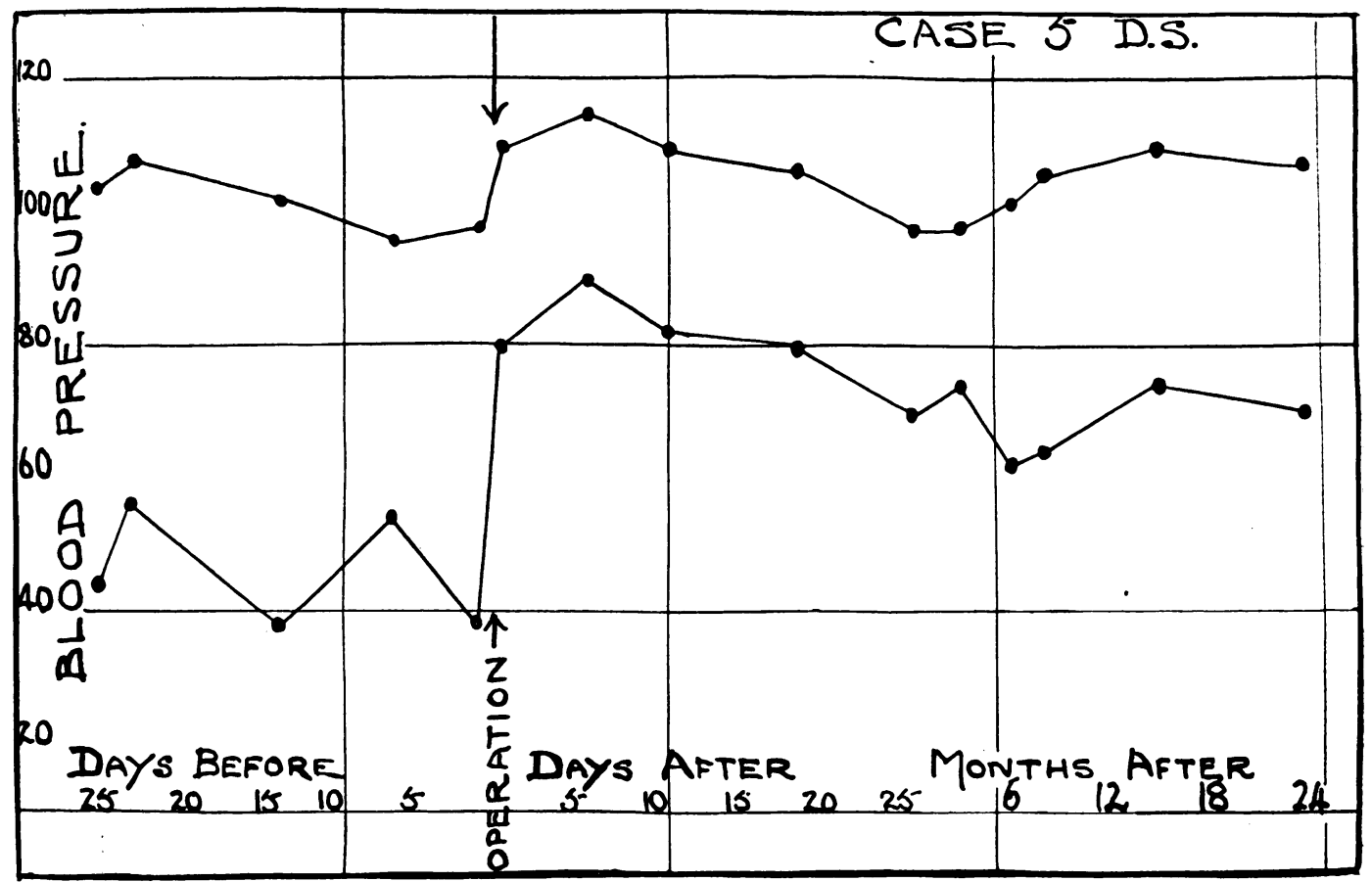

Fig. 13.- Response of the blood pressure to surgical ligation in Case 5. Two years after operation the diastolic pressure is maintained around $70 \mathrm{~mm}$. as compared with a minimum of $38 \mathrm{~mm}$. before ligation. Teleradiograms of this boy's heart are reproduced in Fig. 12.

pleural effusion, from the effects of which he only slowly made substantial headway. Considerable pleural thickening and minor degree of pulmonary fibrosis persist with diminished thoracic expansion. In spite of this he is remarkably well and able for strenuous exercise.

Of the children, Case 10 may be selected. Although a trifle in excess of the standard weight, this boy presented well-marked physical signs and a minor degree of incapacity. Surgical ligation caused little disturbance. He had no post-operative complications and four months later the transverse diameter of his heart had decreased by $1.6 \mathrm{~cm}$. and his pulmonary index by $0.5 \mathrm{~cm}$.

In three patients the response has been assessed as "fair", i.e. a minor degree of improvement, less than anticipated. Case 4, a medical student, had the ductus incompletely occluded by a silver ring. In spite of persistence of the Gibson murmur in a modified form, the transverse cardiac diameter has decreased from 151 to $143 \mathrm{~mm}$. and he expresses himself as convinced of the benefit which he has obtained. Case 7 so far ( 7 months) shows little improvement for though the diastolic blood pressure is reasonably well maintained (see Fig. 14), $\mathrm{X}$-ray examination suggests that the ductus is not completely occluded. The Gibson murmur returned on the sixth day after operation and persists, though fainter than formerly. This child has not gained weight. Similarly, Case 11-a neglected slum child-though the physical defect has been completely corrected, has not after six months improved in a nutritional sense.

The result has been classified as " poor" in one patient-Case 6. This boy has obtained no benefit though he continues to gain weight slowly. His physical signs returned on the third day after operation. From the appearances of his heart, the vascularity of his lung, and the fall in his diastolic blood pressure, now as low or lower than before operation, it can only be concluded that the ligatures slipped and his ductus is now as widely patent as before operation (Fig. 15). An analysis of the results obtained up to date is incorporated in Table V. 
TABLE V

The Effect of Surgical Occlusion of the Ductus on Certain Bodily Measurements

\begin{tabular}{|c|c|c|c|c|c|c|c|c|c|c|c|}
\hline \multirow{2}{*}{$\begin{array}{l}\text { Case No., } \\
\text { sex, and } \\
\text { Age }\end{array}$} & \multirow{2}{*}{ Occupation } & \multirow{2}{*}{$\begin{array}{l}\text { Time in } \\
\text { relation to } \\
\text { ligation }\end{array}$} & \multirow{2}{*}{ 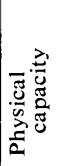 } & \multicolumn{2}{|c|}{ Heart size } & \multicolumn{2}{|c|}{$\begin{array}{l}\text { Blood } \\
\text { pressure }\end{array}$} & \multirow{2}{*}{$\begin{array}{c}\text { Pleural } \\
\text { effusion } \\
\text { after } \\
\text { opera- } \\
\text { tion }\end{array}$} & \multirow{2}{*}{$\begin{array}{l}\text { Dia- } \\
\text { phrag- } \\
\text { matic } \\
\text { paresis } \\
\text { after } \\
\text { opera- } \\
\text { tion }\end{array}$} & \multirow{2}{*}{ Result } & \multirow{2}{*}{ Remarks } \\
\hline & & & & m.t.d. & P.A.I. & Syst. & Diast. & & & & \\
\hline \multirow[t]{2}{*}{ 2. m. $4 \frac{1}{2}$} & \multirow[t]{2}{*}{ Schoolboy } & $\begin{array}{l}\text { Before } \\
3 \text { mth. after }\end{array}$ & $\begin{array}{l}2 \\
1\end{array}$ & $\begin{array}{l}96 \\
90\end{array}$ & $\stackrel{?}{?}$ & $\begin{array}{r}80 \\
108\end{array}$ & $\begin{array}{l}34 \\
70\end{array}$ & Yes & No & Good & Ductus re-canalized later. \\
\hline & & $\begin{array}{l}\text { Before } \\
7 \text { days after }\end{array}$ & $\underline{2}$ & $\underline{90}$ & $\stackrel{?}{-}$ & $\begin{array}{r}94 \\
110\end{array}$ & $\begin{array}{l}30 \\
66\end{array}$ & Yes & No & Death & Died from hæmorrhage. \\
\hline 3. $\mathrm{m} \cdot 18$ & Clerk & $\begin{array}{l}\text { Before } \\
3 \frac{3}{4} \text { yr. after }\end{array}$ & $\begin{array}{l}3 \\
1\end{array}$ & $\begin{array}{l}150 \\
135\end{array}$ & $\begin{array}{l}85 \\
85\end{array}$ & $\begin{array}{l}150 \\
124\end{array}$ & $\begin{array}{l}50 \\
84\end{array}$ & Yes & No & Good & $\begin{array}{l}\text { Murmur returned tempo- } \\
\text { rarily. }\end{array}$ \\
\hline 4. m. 21 & $\begin{array}{l}\text { Medical } \\
\text { student }\end{array}$ & $\begin{array}{l}\text { Before } \\
3 \text { yr. after }\end{array}$ & $\begin{array}{l}2 \\
2\end{array}$ & $\begin{array}{l}151 \\
143\end{array}$ & $\begin{array}{l}93 \\
93\end{array}$ & $\begin{array}{l}130 \\
120\end{array}$ & $\begin{array}{l}52 \\
56\end{array}$ & Yes & No & Fair & $\begin{array}{l}\text { Incomplete occlusion by } \\
\text { silver ring. }\end{array}$ \\
\hline 5. m. 13 & Schoolboy & $\begin{array}{l}\text { Before } \\
2 \text { yr. after }\end{array}$ & $\begin{array}{l}4 \\
1\end{array}$ & $\begin{array}{l}112 \\
114\end{array}$ & $\begin{array}{l}73 \\
59\end{array}$ & $\begin{array}{r}98 \\
108\end{array}$ & $\begin{array}{l}38 \\
70\end{array}$ & Yes & No & Excellent & $\begin{array}{l}\text { Perfect health. Gain of } \\
43 \mathrm{lb} \text {. in weight. }\end{array}$ \\
\hline 6. m. 13 & Schoolboy & $\begin{array}{l}\text { Before } \\
7 \text { mth. after }\end{array}$ & 2 & $\begin{array}{l}132 \\
132\end{array}$ & $\begin{array}{l}71 \\
72\end{array}$ & $\begin{array}{l}90 \\
88\end{array}$ & $\begin{array}{l}48 \\
46\end{array}$ & No & Yes & Poor & $\begin{array}{l}\text { General health i.s.q. } \\
\text { Ductus reopened. }\end{array}$ \\
\hline 7. f. 5 & Schoolgirl & $\begin{array}{l}\text { Before } \\
6 \text { mth. after }\end{array}$ & 2 & $\begin{array}{l}87 \\
88\end{array}$ & $\begin{array}{l}52 \\
54\end{array}$ & $\begin{array}{r}86 \\
102\end{array}$ & $\begin{array}{l}44 \\
62\end{array}$ & Yes & Yes & Fair & $\begin{array}{l}\text { Murmur returned but } \\
\text { blood pressure main- } \\
\text { tained. }\end{array}$ \\
\hline 8. f. 7 & Schoolgirl & $\begin{array}{l}\text { Before } \\
4 \text { mth. after }\end{array}$ & $\begin{array}{l}2 \\
1\end{array}$ & $\begin{array}{l}88 \\
97 *\end{array}$ & $\begin{array}{l}52 \\
54\end{array}$ & $\begin{array}{r}82 \\
100\end{array}$ & $\begin{array}{l}52 \\
74\end{array}$ & No & Yes & Good & Health improving steadily \\
\hline 9. m. 18 & Shipwright & $\begin{array}{l}\text { Before } \\
3 \text { mth. after }\end{array}$ & $\begin{array}{l}2 \\
1\end{array}$ & $\begin{array}{l}130 \\
137 *\end{array}$ & $\begin{array}{l}80 \\
75\end{array}$ & $\begin{array}{l}110 \\
135\end{array}$ & $\begin{array}{l}60 \\
90\end{array}$ & Yes & Yes & Good & Very well. \\
\hline 10. m. 6 & Schoolboy & $\begin{array}{l}\text { Before } \\
4 \text { mth. after }\end{array}$ & $\begin{array}{l}2 \\
1\end{array}$ & $\begin{array}{r}112 \\
96\end{array}$ & $\begin{array}{l}60 \\
55\end{array}$ & $\begin{array}{l}102 \\
100\end{array}$ & $\begin{array}{l}46 \\
70\end{array}$ & No & No & Good & Very well. \\
\hline 11. f. 8 & Schoolgirl & $\begin{array}{l}\text { Before } \\
3 \text { mth. after }\end{array}$ & $\begin{array}{l}2 \\
2\end{array}$ & $\begin{array}{l}96 \\
97 *\end{array}$ & $\begin{array}{l}55 \\
49\end{array}$ & $\begin{array}{r}94 \\
108\end{array}$ & $\begin{array}{l}34 \\
75\end{array}$ & No & Yes & Fair & Slow improvement. \\
\hline 12. f. 10 & Schoolgirl & $\begin{array}{l}\text { Before } \\
1 \mathrm{mth} \text {. after }\end{array}$ & $\frac{2}{-}$ & 104 & 54 & $\begin{array}{l}126 \\
120\end{array}$ & $\begin{array}{l}62 \\
80 \\
\end{array}$ & Yes & No & Death & Died; ? mediastinitis. \\
\hline 13. f. 8 & Schoolgirl & $\begin{array}{l}\text { Before } \\
4 \text { mth. after }\end{array}$ & $\begin{array}{l}2 \\
1\end{array}$ & $\begin{array}{l}117 \\
111\end{array}$ & $\begin{array}{l}64 \\
66\end{array}$ & $\begin{array}{r}82 \\
125\end{array}$ & $\begin{array}{l}46 \\
75\end{array}$ & Yes & No & Good & Improving steadily. \\
\hline
\end{tabular}

Two Cases of Subacute Bacterial Endarteritis

\begin{tabular}{l|l|l|l|l|l|l|l|l|l|l|l|l} 
1. m. 19 & Van driver & $\begin{array}{l}\text { Before } \ldots \\
3 \text { days after }\end{array}$ & - & - & - & 110 & 42 & No & No & Death & Pulmonary collapse. \\
\hline 14. f. 28 & Housewife & $\begin{array}{l}\text { Before } \ldots \\
\text { 3 days after }\end{array}$ & 6 & -152 & 94 & 145 & 42 & Yes & No & Death & Pulmonary collapse. \\
\hline
\end{tabular}

Physical capacity has been assessed for each patient before and after operation according to the same scale as in Table IV (see p. 16).

The age given for each patient is that at the time of operation. is employed as a rough measure in $\mathrm{mm}$. of the size of the pulmonary artery (Evans, 1943).

The minimum blood pressure reading in the period before operation is recorded for each patient to compare with the level at which The minimum blood pressure reading in the period before operation is recorded for each patient to compare with the level at which the blood pressure eventually becomes stabilized after operation.

The occurrence of a pleural effusion or a left-sided diaphragmatic paresis is recorded for each patient in the period after operation.

The clinical assessment of the patient's response to surgery is inserted under " Result."

* A slight tilt imparted to the heart by the elevation of the left dome of the diaphragm makes comparative measurements of the transverse cardiac diameter difficult.

Summary. To summarize these findings, observation of the 14 patients in the period after operation has shown distinct improvement in the general health and physical capacity in 6 (Cases 3, 5, 8, 9, 10, and 13). It is natural that the degree of improvement should be more obvious in the older patients as their physical handicap was greater than that of the younger members of the group. It is satisfactory that these six patients have been restored to normal health and full activity. Cases 4, 6, 7, and 11 have obtained less benefit than anticipated, chiefly for the reason that only partial obliteration of the ductus was obtained in three of them. Two patients, submitted to operation on account of bacterial endarteritis, died shortly afterwards. Two non-infected cases died.

\section{Problems of the Post-Operative Period}

The patient in this period requires constant care and attention. Most have been nursed for 24 to 48 hours in the oxygen tent with considerable benefit. There are features after the 


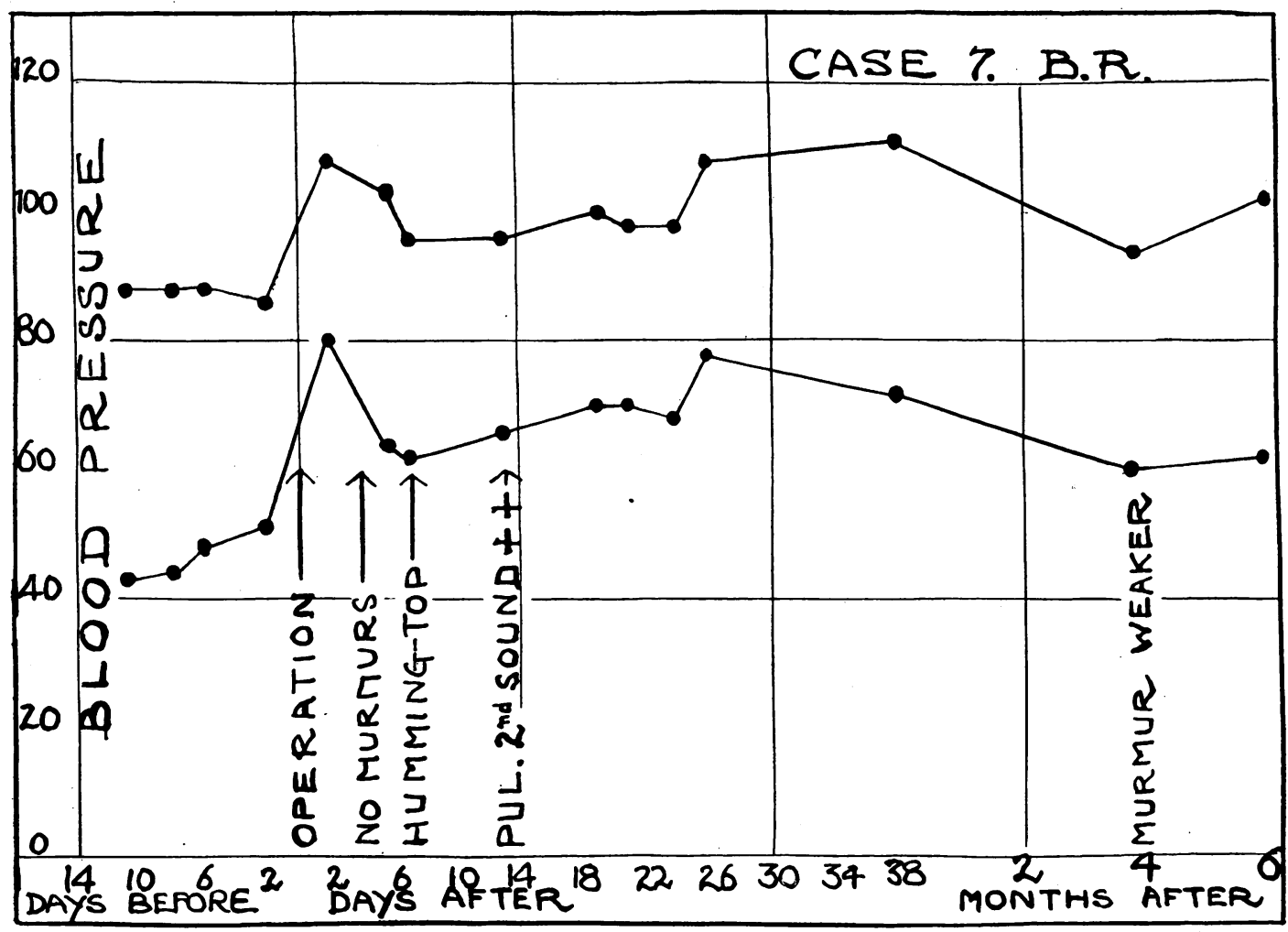

Fig. 14.-Blood pressure response in Case 7. The Gibson murmur returned on the sixth day after operation. Radiological evidence confirmed the re-establishment of the fistula. In spite of this the diastolic pressure is more satisfactory than previously and four months after operation the ductal murmur is weaker than before.

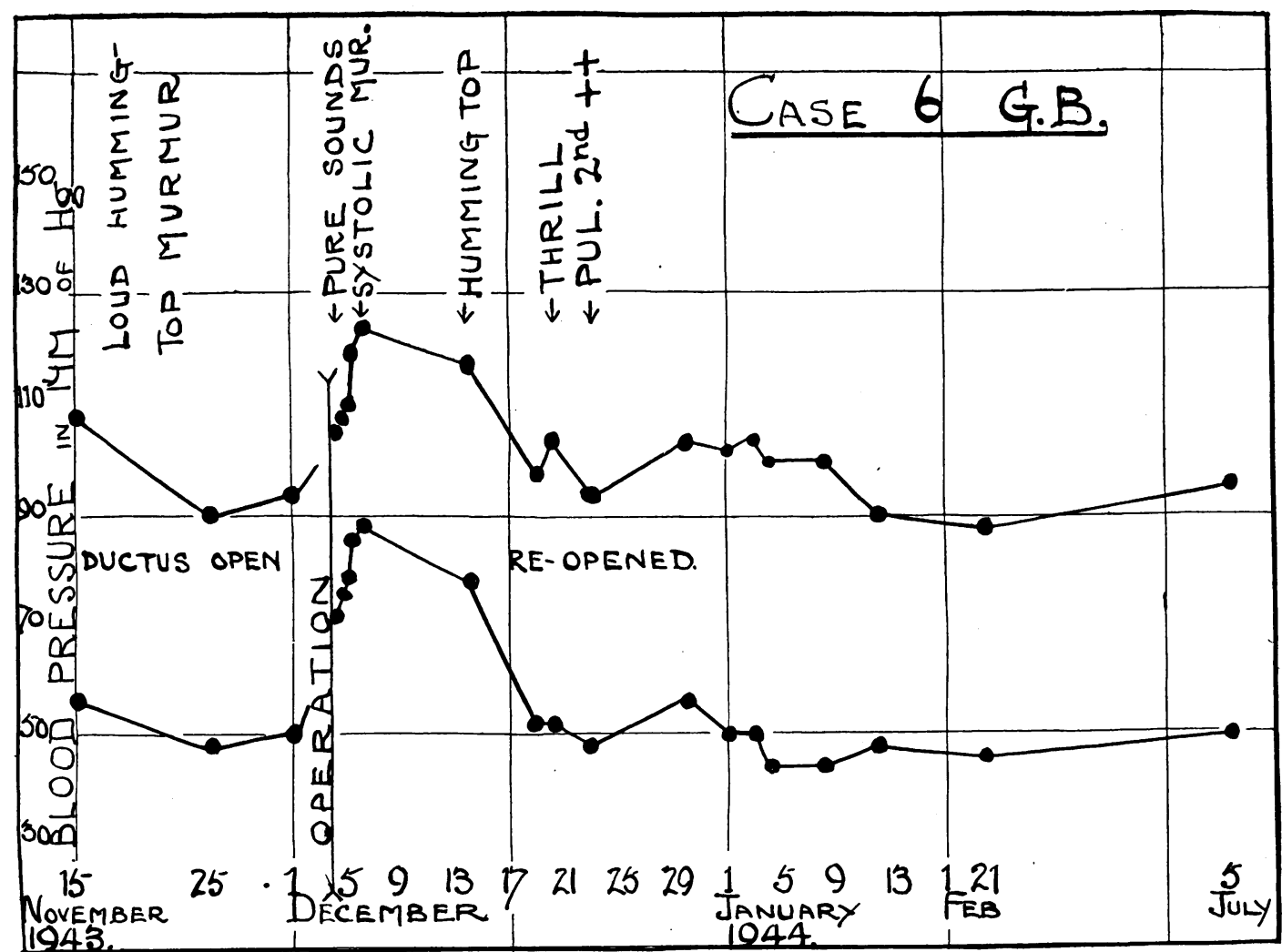

FIG. 15.-Blood pressure response in Case 6. The first indication of re-establishment of the ductal channel was a systolic murmur observed on the third day after operation. The Gibson murmur was recognized on the eleventh day. A week later the blood pressure had fallen and physical signs were then fully developed. 
operation that are confusing and difficult to interpret, particularly in relation to the state of the lungs.

Respiratory Complications. Physical signs in the chest are notoriously difficult to interpret after the pleura has been opened, and in acutely ill patients with cumbersome dressings the examination of the lungs can be very difficult. Radiological control is essential. Considerable experience is required in the interpretation of the films (Cleland and Rackow, 1943). Blood in the form of a large hæmatoma of the chest wall at the site of the operative approach can cast a shadow in the radiogram which may at first simulate a hæmothorax, and later, when resolution is in progress, a minor haziness suggestive of a partial atelectasis. Air and blood in the pleura are common. Familiarity with the radiological appearances after operations in the chest is of enormous help in understanding the respiratory complications of the first ten days. It is questionable whether at the conclusion of the operation re-expansion of the lung by intratracheal positive pressure is the best method, in view of the risk of driving accumulated secretion deeply into the alveoli and thereby favouring local collapse and infection. To avoid the risk of stagnation in the collapsed lung, Jones (1940) recommends the use of repeated positive pressure to re-expand the entire lung for a few seconds every 10 or 15 minutes while the pleura is open. Gross (1944) now employs intra-pleural suction to re-expand the collapsed left lung at the conclusion of the operation.

Experience indicates the desirability of withdrawing pleural fluid from the chest. Blood should not be left in the pleural sac. Lush and Nicholson (1944) in emphasizing the advantages of evacuation of the mass of clot in a clotted hæmothorax as the quickest way of restoring respiratory function and preventing infection, point out that the diagnosis is often confused with consolidation, and is confirmed by repeated failed aspirations. This is an aspect of post-operative care warranting close attention, where repeated frontal and lateral X-rays are of the greatest value in conjunction with the clinical findings. Respiratory exercises, oxygen enriched with $\mathrm{CO}_{2}$, and stimulant expectorants should be started at the first opportunity in the hope of reducing the liability to massive pulmonary collapse.

Recanalization of the Ductus. It is not uncommon for the Gibson murmur to return. In the series of 107 non-infected cases collected by Shapiro and Keys (1943) a continuous murmur persisted after ligation in 14, which may well be an under-estimate of its frequency. Employing light compression of the ductus with two heavy braided silk ligatures and a cellophane wrap, better results were obtained by Gross (1944) than by simple ligation alone. In only 3 of 28 patients in whom cellophane was employed along with double silk ligatures have minimal leaks persisted since operation. On account of these failures Gross (1944) has introduced a new technique for the complete surgical division of the ductus.

It is reasonable to assume that a return of the Gibson murmur signifies a re-establishment of the fistula between the aorta and the pulmonary artery, but attention must be paid to the remarkable observation of Touroff and Vesell (1940) who found that the loud machinery murmur persisted in one patient after the ductus had been divided and the stumps ligated close to the pulmonary artery and aorta respectively. Now that Gross (1944) has introduced and recommended division of the ductus, confirmation of this curious observation should be forthcoming. In two patients Touroff and Vesell (1940) noted in the course of the operation that on occlusion of the ductus there was a diminution of the thrill and murmur, both of which could be abolished when the pulmonary artery was lightly compressed. This suggests that the tension of the wall of the pulmonary artery is a factor in the production of the murmur, but it is difficult to understand how a dilated artery can in itself be responsible for the diastolic element or the continuous quality of the murmur. Peacock (1858) has described a case in which the ductus existed in duplicate. Arising from the aorta, one branch united with the right pulmonary artery, the other with the left. It is possible that under similar circumstances one branch might be ligated, the other persist and produce the murmur.

It is worth recalling that a wide open ductus may fail to produce a murmur (Keys and 
Shapiro, 1943). In Case 4 of this series, although the ductus was only partially occluded, the continuous murmur, previously well heard, could not always be recognized during the first 14 days after operation; a systolic murmur took its place ; later the Gibson murmur returned and has persisted in the three years since operation. Similarly in childhood the murmur develops slowly, the age of 4 being commonly reached before its continuous quality enables it to be recognized with certainty. It is therefore true that patency of the ductus can exist in the absence of the continuous murmur. On the basis of the size of the channel and differences in blood pressure between the two circuits, the absence of the murmur on certain occasions is more readily acceptable than its presence when no fistula does in fact exist. For clinical purposes it is wiser to assume, unless proved otherwise, that a return of the murmur signifies a recanalization of the channel.

In the present series of 15 operations done on 14 patients, the ductus was closed on 12 occasions. In one patient (Case 4) a silver ring produced partial obliteration and in two other patients (Case 1 and Case 2, second operation) satisfactory occlusion was impossible on account of local hæmorrhage. Of the remaining 12 surgical occlusions, the typical continuous murmur of a patent ductus developed in the period after operation in 4 instances (Cases 2, first operation, 3, 6, and 7). The related facts are conveniently grouped in Table VI.

TABLE VI

Return of Gibson Murmur after Surgical Ligation

\begin{tabular}{|c|c|c|c|c|c|c|c|}
\hline Case No. & $\begin{array}{l}\text { Ligature } \\
\text { material }\end{array}$ & $\begin{array}{l}\text { Number } \\
\text { of days } \\
\text { before } \\
\text { murmur } \\
\text { returned }\end{array}$ & $\begin{array}{l}\text { X-ray } \\
\text { appear- } \\
\text { ances }\end{array}$ & $\begin{array}{l}\text { Fall in } \\
\text { diastolic } \\
\text { B.P. }\end{array}$ & $\begin{array}{l}\text { Present } \\
\text { state of } \\
\text { murmer }\end{array}$ & $\begin{array}{l}\text { Present } \\
\text { state of } \\
\text { patient }\end{array}$ & Remarks \\
\hline 2 & $\begin{array}{l}\text { Heavy } \\
\text { catgut }\end{array}$ & $60 \pm$ & + & 40 & - & Died & $\begin{array}{l}\text { Recanalization of ductus } \\
\text { confirmed at second } \\
\text { operation. }\end{array}$ \\
\hline 3 & $\begin{array}{l}\text { Heavy } \\
\text { silk (2) }\end{array}$ & 11 & $?$ & $20 \pm$ & & Good & $\begin{array}{l}\text { No murmurs now; B.P. } \\
\text { maintained. }\end{array}$ \\
\hline 6 & $\begin{array}{l}\text { Heavy } \\
\text { silk (2) }\end{array}$ & 10 & & 40 & $\begin{array}{l}\text { Persists } \\
9 \text { months }\end{array}$ & Poor & Health in statu quo. \\
\hline 7 & $\begin{array}{l}\text { Linen } \\
\text { tape }\end{array}$ & 6 & ++ & 25 & $\begin{array}{l}\text { Persists } \\
7 \text { months }\end{array}$ & Fair & $\begin{array}{l}\text { Health fair; B.P. main- } \\
\text { tained. }\end{array}$ \\
\hline
\end{tabular}

When the ductus re-opens the first clinical evidence is the detection of a basal systolic murmur, This was observed in Case 6 as early as the third day after operation. It increased in intensity without appreciable change in the level of the diastolic blood pressure until the eleventh day, when the distant continuous hum was first recognized. Thereafter the blood pressure fell and further local signs developed (Fig. 15). On the other hand the typical murmur returned in Cases 3 and 7 with little or no significant alteration in blood pressure (Fig. 16 and 14). In spite of this the ductus was undoubtedly reconstituted in Case 7, as fully developed radiological signs persisted. In Case 3 the presence of post-operative pulmonary collapse, an effusion, and a certain amount of residual fibrosis, made the state of the pulmonary artery and the ventricular excursion difficult to determine. It is remarkable that since the Gibson murmur has finally disappeared a " hilar dance " is evident on screen examination of this boy's chest.

The return of the murmur suggests either a slipping of the knot as a result of its repeated exposure at each heart beat to the strain of the increased blood pressure, or else it may be that the vascular channel is re-established as a result of pressure erosion by the ligature. It was certainly unexpected to find that a structure which normally obliterates itself within a few months of birth should fail to do so when given the opportunity in later life. The problem of satisfactory occlusion is not yet solved, though Ballance and Edmunds (1891) many years ago enunciated the principles involved in the closure of large arteries. The tension with which the knot is tied must be sufficient to approximate 


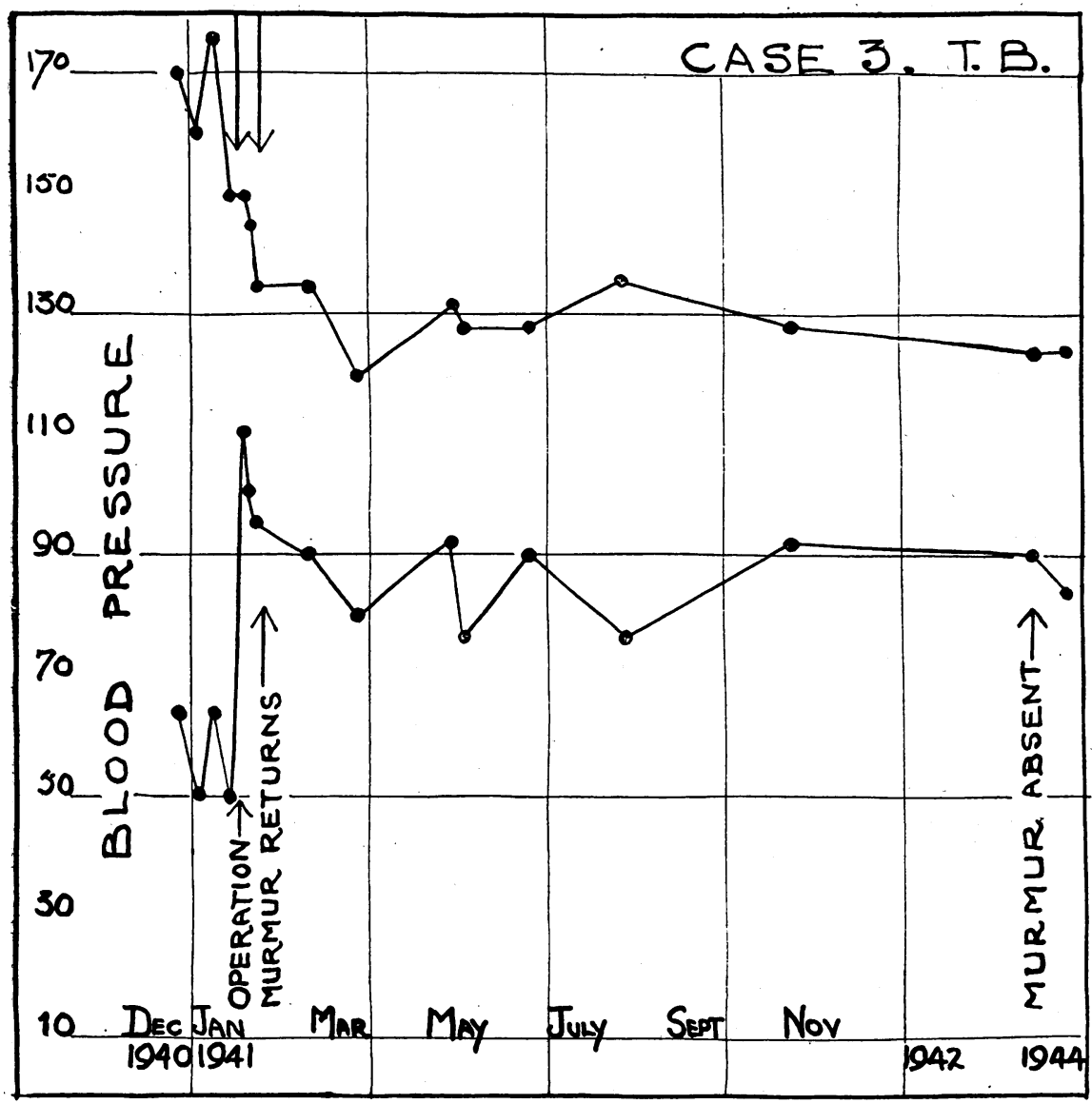

Fig. 16.-Blood pressure response in Case 3. The ductus was ligated in January 1941. The typical murmur returned eleven days after operation and persisted for at least eleven months. When re-examined in February and July 1944 no murmurs could be detected. The blood pressure is well maintained throughout. The effect of ligation on the pulse pressure is striking, the average before operation being $100 \mathrm{~mm}$. and three and a half years after ligation $\mathbf{4 0} \mathrm{mm}$.

the intimal surfaces but not great enough to rupture either the inner or middle coats. Similarly, the material employed must be of a size appropriate to the bore of the vessel, the ductus being often as wide as the aorta. Pearse (1940) has successfully applied the observation of Page (1939) on the constrictive effect of cellophane wrapped loosely round the kidney, to the problem of the gradual occlusion of large arteries. Cellophane excites an intense local reaction, causes a steady and progressive constriction at the site of application, and even in 6 or 8 weeks may produce complete obliteration of the lumen of the dog's aorta. The use of cellophane to ensure obliteration of the ductus was suggested by Holman (1940b) and has met with considerable success. It can be sterilized by exposure to alcohol or mercury oxycyanide for 12 hours. After the ductus has been ligated with silk in two places and the ends of each knot securely held by clips, a length of cellophane folded into strips about four layers thick is wrapped loosely round the ductus between the ligatures, and its ends tied by catgut (Gross, 1942). Since employing this technique we have not noted a return of the murmur nor any evidence to suggest recanalization. Gebauer (1943) has had failures with this method, as has had Gross (1944), but the results obtained with cellophane are superior to simple ligation and less dangerous than division. The perfect solution to the problem of ligation has not yet been found, but it would appear to consist in a cellular reaction initiated by the application of a reagent locally.

Blood Pressure after Operation. Reference has already been made to the value of blood pressure readings in diagnosis. On closure of the ductus the blood pressure, particularly the diastolic, promptly rises, even above normal. Bourne (1941) has described how in one of his patients a defect in renal function, as measured by the urea clearance test, was evident during this phase: by way of explanation, he suggests that a reflex spastic state of the peripheral and glomerular arterioles accounts for both phenomena. 
The maximum blood pressure readings are usually observed within the first two or three days of operation. Thereafter the diastolic pressure falls gradually over a period of a month or more before it becomes finally stabilized, usually about 20 to $30 \mathrm{~mm}$. below the maximum levels recorded in the first few days. In this series the highest diastolic pressure recorded after operation was in Case 9. Before operation his readings were 110/60, on the third day after, $144 / 112$, and three months later 135/90. His blood volume fell from 3360 c.c. per sq. $m$. to 2830 c.c., the latter being within the normal range for build (Davis, 1942). It is probable that the excess blood volume plays a part in the production of the high blood pressure. We have not made observations on water-balance and renal function after operation. One child (Case 11) had an abrupt rise to $158 / 94$ eight hours after operation, her previous readings having been as low as $94 / 34$.

We have satisfactory figures before and after operation in 10 patients, minimum readings being compared in each instance. On the average the diastolic blood pressure ultimately becomes stabilized at a level $30 \mathrm{~mm}$. higher than before ligation. In 3 patients with incomplete closure in whom local signs of patency persisted (Cases 1, 4, and 7) the average rise in diastolic pressure was $15 \mathrm{~mm}$. The course of the blood pressure response in Case 3 is of interest. Despite the fact that the Gibson murmur returned early and persisted for at least 11 months, there was little disturbance of the blood pressure (Fig. 16). Three years after operation the murmur was absent, without significant alteration in the diastolic pressure. His pulse pressure before operation was $100 \mathrm{~mm}$. and three years later $40 \mathrm{~mm}$. From these facts it is permissible to conclude that with the passage of time local fibrosis initiated by the surgical ligation has finally led to the complete obliteration of the ductus.

\section{THE INDICATIONS FOR SURGERY}

Before recommending surgical treatment the physician must endeavour to weigh the immediate operative hazards against the risks of non-intervention, in the light of the benefits likely to accrue from a successful ligation. This is often a problem of great difficulty, in the solution of which the salient facts gathered from the present series may prove of help.

It is true that a proportion of patients with patency of the ductus live to middle age, and follow active and useful careers, being little the worse for the congenital flaw, but they are in the minority. By the time the age of 40 to 50 is reached the lesion is exceedingly rare. In childhood it is difficult, if not impossible, to select with certainty those patients who in the natural course of events may expect to reach the age of 30 . It is highly probable that when the physical signs are gross, the heart enlarged, the pulse pressure greatly increased, and the response to effort even slightly impaired, the child or young adult has a life-span appreciably less than the average. Hence it is probable that those patients who survive to the third or fourth decade have minimal physical signs in early life-a soft murmur, a heart of normal size, and a blood pressure but little disturbed. They are active people, capable of cultivating many interests, but their expectation of life is reduced, though not to the same extent as in the former group that have more pronounced signs and symptoms.

The need for surgery is more obvious in the symptomatic group, particularly if there be evidence to suggest the early onset of congestive heart failure. The justification for recommending a major surgical procedure in the second group, whose signs and symptoms are minimal, is on less secure grounds, and yet there is good reason for believing that surgical ligation can prevent future difficulties and prolong life. Surgery can restore bodily nutrition, correct under-development, abolish circulatory symptoms, prevent the onset of congestive heart failure, and probably forestall the most serious of all complications, subacute bacterial endarteritis. There is, therefore, much to be said in support of the views of Vedoya (1942) and his colleagues who urge that operation should be undertaken as early as possible in every case of patent ductus.

Unfortunately the operative risks are considerable. If surgery was as safe and as certain 
in its results as in other disorders of childhood, there would certainly be less hesitation in recommending ligation. Apart from injury to the ductus, exsanguinating hæmorrhage, and a stormy convalescence with the risk of serious respiratory complications, there is also the possibility of a deep-seated infection. There is, however, every reason to assume that as surgical technique improves, as knowledge of the most certain means of ductal obliteration increases, and as experience of appropriate post-operative care of the lungs develops, so in the future a reduction in operative mortality can be confidently anticipated, and a shorter and less tiresome convalescence assured. Of the 107 non-infected cases collected by Shapiro and Keys (1943) there were 9 deaths after operation, more than half the ligations being done by two surgeons-Gross (1944) and Jones (1940). With further experience the mortality rate may be reduced to 5 per cent in non-infected cases.

As pointed out by Gebauer (1943), age is an important factor in the selection of suitable patients for this procedure. It is well known that children tolerate intra-thoracic interference better than adults. Edwards (1939) in a series of 199 cases of bronchiectasis treated by lobectomy had no deaths amongst 38 children between the ages of 4 and 16, whereas during the fourth decade his mortality rate was 30 per cent. The speed with which a child under 10 will rally after ductal ligation is remarkable. Gross (1939) has had children out of bed 24 hours after operation and ambulatory on the third day.

In addition to their tolerance for this operation, there are other good reasons for selecting childhood as the most favourable time for operation. Under the age of 10 years, the ductus is as a rule longer, more readily approached and defined, and the operative field less circumscribed: this facilitates ligation. As age increases, even in the 'teens, the pulmonary artery grows larger, encroaches on and even over-rides the aorta, and with this the ductus tends to be shorter, wider, and perhaps flimsier and more inaccessible: in consequence ligation becomes increasingly difficult. By the age of 20 or 30 atheromatous changes about its orifice with sclerosis of its walls predispose to tearing of the coats when the ligatures are applied. For these reasons younger patients make the better subjects.

This does not imply that at first recognition the non-infected ductus warrants a recommendation for surgery. The physician must be guided by the progress of the patient, who should be under observation from time to time for six months as a minimum. There is always the possibility that the ductus may close spontaneously. If it has not done so by the age of 9 or 10 , and the physical signs remain gross, then the risks should be faced in the hope of rendering the future more secure.

To justify operation between the age of 10 and 20 , the patient's disability must be more severe than in the younger group. At this time pathological changes begin to make their appearance in the pulmonary artery and with every additional year of age the patient's immediate reaction to the surgical disturbance is likely to be more severe. After 20 there is at present little justification for recommending surgery, as by adapting themselves to their limitations many of these patients will keep reasonably well and sufficiently fit to follow an occupation. Should symptoms become more severe, or congestive heart failure threaten or appear, then after suitable preparation surgical ligation should be recommended. The risks are greater than in younger people, but are justified in that when signs of heart failure appear clinical experience indicates that on medical measures alone this form of congenital heart disease runs a rapid downward course.

It may, therefore, be said that in selecting patients for surgery the main factors to consider are the age and the degree of cardiac embarrassment. In general the younger patient should be accepted for surgery when symptoms are minimal, in the hope that thereby he may grow and develop normally, and be safeguarded from the killing complications that we know may shorten life. In older patients, on account of the operative hazards, surgery can be justified when symptoms, being more severe, warrant the risk. In the presence of an infected ductus surgery is the treatment of choice and it should be undertaken without delay, at any age. 
In my opinion surgical ligation of the ductus arteriosus is an outstanding contribution to cardiac therapy. Admittedly the numbers are few, the patients a select group, and the treatment highly specialized and technical, but in no other branch of cardiology are the ultimate results likely to be so perfect. As a technical achievement it is one of the most dramatic and inspiring of operative procedures, demanding the dexterity, courage, forbearance, and resourcefulness that we associate with the highest surgical talents.

\section{SUMMARY}

Patency of the ductus arteriosus has been studied in a series of 28 consecutive patients, 14 of whom were submitted to surgical ligation.

In diagnosis emphasis is placed on the almost pathognomonic sign-the continuous murmur of Gibson. In the absence of the characteristic murmur the diagnosis can still be established by the detection of other signs which taken together are of almost equal value. In order of importance these are pulmonary artery dilatation, an increased pulse pressure at rest or after exercise, and a long harsh basal systolic murmur with an accentuated or reduplicated pulmonary second sound.

The defect is in the nature of an arterio-venous fistula. In patent ductus arteriosus the ventricular outputs are unequal, the left exceeding the right by the amount of flow through the ductus. This in turn is regulated, at least in part, by the size of the channel and the degree of resistance offered by the peripheral arterioles of the pulmonary circuit, the constriction of which decreases the burden thrown on the left ventricle by correcting the tendency to an excessive fall in diastolic pressure.

Most cases are observed in childhood and 70 per cent are detected before the age of 20 is reached. After this the condition becomes increasingly rare. The scanty number of adults so affected can be explained on several grounds, such as death in youth, spontaneous closure of the ductus in childhood, or on the failure of the clinician and pathologist to look for this lesion systematically in older patients.

Of 14 patients (Cases 15-28) in whom surgery was judged unnecessary or undesirable, the eldest was 49 and the youngest 5 , with an average age of 20 years. Two died, one from intercurrent infection and one from subacute bacterial endarteritis. Slight deterioration in physical capacity was observed in three patients. Two women married and have borne families without undue distress. In one patient, a boy of 6 , the ductus closed spontaneously.

Of the 14 patients submitted to surgery distinct improvement in the general health and physical capacity was observed in six. Four obtained less benefit than anticipated, chiefly because complete obliteration of the ductus was not always obtained. Two patients died in the period after operation.

The diagnosis of the infected ductus is discussed. As an aid to its recognition emphasis is placed on the value of repeated X-ray examinations. The radiological appearances are, on occasions, unique: the changing pattern of the heart and lungs makes a sequence so characteristic that the diagnosis of bacterial endarteritis of the ductus and pulmonary artery should seldom be missed.

Two patients submitted to surgery on account of bacterial endarteritis died. Death in each instance was attributed to massive pulmonary collapse.

Problems of the post-operative period are discussed. The occurrence of respiratory complications, recanalization of the ductus after ligation, the significance of a return of the Gibson murmur after operation, and the course of the blood pressure response, are considered.

The selection of patients for surgery demands careful consideration. The main factors to bear in mind are the age of the patient and the degree of cardiac embarrassment. In general the younger patient should be accepted for surgery when symptoms are minimal, in the hope that by ductal occlusion the child may grow and develop normally. In older patients, on 
account of the increasing operative hazards, surgery can only be justified when symptoms, being more severe, warrant the risk. In the presence of an infected ductus ligation should be undertaken without delay at any age.

I take pleasure in acknowledging my indebtedness to many friends and colleagues who have helped me; above all to Sir John Fraser, who has been responsible for the surgical work, and has placed his operation notes at my disposal; his interest and encouragement have been invaluable. I am also grateful to Mr. Walter Mercer for allowing me to include one of his patients in this series. To Dr. G. J. I. Linklater of the Edinburgh School Medical Service, Dr. John Gillies, Dr. J. P. McGibbon, and Dr. Marion Bethune I also express my thanks for their co-operation.

\section{REFERENCES}

Abbott, M. E. (1927). In Osler's Modern Medicine, 3rd edit., London.

(1936). Atlas of Congenital Heart Disease, New York.

Alexander, A. A., Knight, H. F., and White, P. D. (1925). Arch. intern. Med., 36, 712.

Alvarenga: quoted by Walshe, W. H. (1876). A Practical Treatise on the Diseases of the Heart and Great Vessels, 4th edit., London, p. 533.

Balfour, G. W. (1898). Clinical Lectures on Diseases of the Heart and Aorta, 3rd edit., Edinburgh, p. 243.

Ballance, C. A., and Edmunds, W. (1891). Ligation of the Great Arteries in Continuity, London.

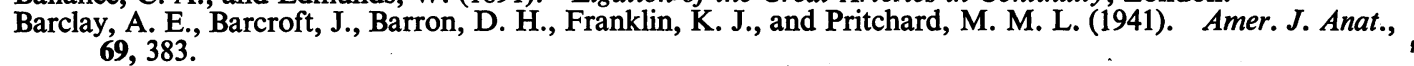

Barcroft, J., Kennedy, J. A., and Mason, M. J. (1938). J. Phys.,92, 1.

Barcroft, J., Barclay, A. E., Barron, D. H., and Franklin, K. J. (1939). Brit. J. Radiol., $12,505$.

Bedford, D. E., Papp, C., and Parkinson, J. (1941). Brit. Heart J., 3, 37.

Bettinger, H. F. (1941). Med. J. Australia, 2, 418.

Bohn, H. (1938). Klin. Wschr., 17, 907.

Boldero, H. E. A., and Bedford, D. E. (1924). Lancet, 2, 747.

Botallus, L. (1660). Opera Omnia Medica et Chirurgica, edited by J. van Horne. Observatio III: Vena arteriarium nutrix a nullo antea notata, Gaasbeeck, p. 66.

Bourne, G., Keele, K. D., and Tubbs, O. S. (1941). Lancet, 2, 444.

Bourne, G. (1941). Brit. Heart J., 3, 228.

Boyd, J. D. (1937). J. Anat., 72, 146.

Brown, J. W. (1939). Congenital Heart Disease, London, p. 89.

Bullock, L. T., Jones, J. C., and Dolley, F. S. (1939). J. Prediat., 15, 786.

de la Camp (1903). Berlin klin. Wschr., 40, 48.

Christie, A. (1930). Amer. J. Dis. Child., 40, 323.

Cleland, W. P., and Rackow, A. M. (1943). Brit. J. Tuberc., 37, 55.

Davis, L. J. (1942). Edin. Med. J., 49, 465.

Donovan, M. S., Neuhauser, E. B. D., and Sosman, M. C. (1943). Amer. J. Roent., $50,293$.

Drawe, C. E. (1937). Amer. J. Dis. Child., 53, 1470.

Duroziez, P. (1862). Compt. rend. Soc. Biol. Paris, 14, 279.

Eakin, W. W., quoted by Abbott, M. E. (1929). In Blumer's Bedside Diagnosis, London, p. 476.

Edwards, A. T. (1939). Brit. med. J., 1, 809.

Ellis, R. W. B. (1932-33). Proc. Roy. Soc. Med., 26, 511.

Eppinger, E. C., Burwell, C. S., and Gross, R. E. (1941). J. Clin. Invest., 20, 127.

Evans, W. (1943). Brit. Heart J., 5, 205.

Fischer, R., and Schur, M. (1932). Klin. Wschr., 1, 114.

Foulis, J. (1884). Edin. med. J., 29, 1117; 30, 17.

Fraentzel, O. (1866). Virchow's Arch., 43, 420.

Franck, M. F. (1878). Gaz. Hôp., 51, 1115.

Franklin, K. J. (1941). Bull. Hist. Med., 9, 580.

Gebauer, P. W. (1943). Austral. New Zeal. J. Surg., 13, 75.

Gerhardt, C. (1867). Jenaische Z. Med. Naturw., 3, 105.

Gibson, G. A. (1898). Diseases of the Heart and Aorta, Edinburgh, p. 161.

- (1900). Edin. med. J., 8, 1.

- (1906). Med. Press, 1, 572.

Goodman, E. (1910-11). Univ. Penn. med. Bull., 10, 509.

Graham, E. A. (1940). Arch. Surg., 41, 324.

Graybiel, A., Strieder, J. W., and Boyer, N. H. (1938). Amer. Heart J., 15, 621.

Gross, R. E., and Hubbard, J. P. (1939). J. Amer. med. Ass., 112, 729.

Gross, R. E. (1939a). N. England J. Med., 220, 510.

- (1939b). Ann. Surg., 110, 321.

- (1942). Advances in Padiatrics I, London, p. 174.

- (1944). Surg. Gynec. Obstet., 78, 36.

Harrington, S. W. (1943). Proc. Staff Meeting Mayo Clinic, 18, 217.

Harrison, T. R., Dock, W., and Holman, E. (1924). Heart, 11, 337.

Harvey, W. (1628). The Works of William Harvey. Printed for the Sydenham Society, 1847, London, p. 38.

Hayek, H. von (1935). Z. Anat. Entwickelungsges, 105, 15.

Hochsinger, C. (1891). Wiener Klinik, 17, 47.

Holman, E. (1940a). Ann. Surg., 112, 840.

$(1940 b)$. Discussion of paper by Pearse (1940).

Horder, Lord (1940). Personal communication.

Hubbard, J. P., Emerson, P. V., and Green, H. (1939). New England J. Med., 221, 481. 
Hubbard, J. P. (1943). J. Padiat., 22, 50.

Jacobi, A. (1914). Trans. Ass. Amer. Phys., 29, 308.

Jager, B. V., and Wollenman, O. J. (1942). Amer. J. Path., 18, 595.

Jewesbury, R. C. (1912-13). Proc. Roy. Soc. Med., 6, 100.

Jones, J. C., Dolley, F. S., and Bullock, L. T. (1940). J. Thoracic Surg., 9, 413.

Judson, C. F., and Nicholson, P. (1914). Amer. J. Dis. Child., 8, 257.

Katz, L. N., and Wachtel, H. (1937). Amer. Heart J., 13, 202.

Kennedy, J. A. (1942). Amer. J. med. Sci., 204, 570.

and Clark, S. L. (1942). Amer. J. Phys., 136, 140.

Keys, A., and Friedell, H. L. (1939). Ibid., 126, 741

- Garland, L. H., Madrazo, M. F., and Rigler, L. G. (1940). Amer. J. Roent., 44, 805.

Keys, A., and Shapiro, M. J. (1943). Amer. Heart J., 25, 158.

Keys, A., Violante, A., and Shapiro, M. J. (1940). Arch. Lat. Amer. Card. Hamat., 10, 237.

Laubry, C. (1930). Nouveau Traité de Pathologie Interne, Paris, III.*

- and Pezzi, C. (1921). Maladies Congénitales du Ceur, Paris.*

Leech, C. B. (1932). Amer. J. Dis. Child., 43, 1086.

Leeds, S. E. (1942-43). Amer. J. Phys., 139, 451.

Lewis, T., and Drury, A. N. (1923). Heart, 10, 257.

Lush, R. W., Nicholson, J. C., Stevenson, C. R., and Nicholson, W. F. (1944). Lancet, $2,467$.

Muir, W. C., and Brown, J. W. (1932). Arch. Dis. Child., 7, 291.

Munro, J. C. (1907). Ann. Surg., 46, 335.

Noback, G. J., and Rehman, I. (1941). Anat. Rec., 81, 505.

Oberwinter, - (1904). Munchen med. Wschr., 51, 1610.

Page, I. H. (1939). J. Amer. med. Ass., 113, 2046.

Peacock, T. B. (1858). On Malformations of the Human Heart, London, p. 89.

Pearse, H. E. (1940). Ann. Surg., 112, 923.

Roesler, H. (1936). Clinical Roentgenology of the Cardiovascular System, London, p. 276.

Schnitker, M. A. (1940). The Electrocardiogram in Congenital Heart Disease, Cambridge, Massachusetts.

Schrotter, H. (1901). Z. klin. Med., 43, 160.

Shapiro, M. J., and Keys, A. (1943). Amer. J. med. Sci., 206, 174.

Smith, K. S. (1929). Arch. Dis. Child., 4, 330.

Stewart, W. H., Breeiner, C. W., and Maier, H. C. (1941). Amer. J. Roent., 46, 636.

Steinberg, M. F., Grishman, A., and Sussman, M. L. (1943). Ibid., 50, 306.

Swensson, A. (1939). Z. mikr.-anat. Forsch., 46, 275.

Tileston, W. (1910). J. Amer. med. Ass., 55, 2210.

Touroff, A. S. W., and Vesell, H. (1940). Ibid., 115, 1270.

(1940), J. Thoracic Surg., 10, 59.

Touroff, A. S. W. (1942a). Amer. Heart J., 23, 847.

- (1942b). Surgery, $12,24$.

- (1942c). J. Thoracic Surg., 12, 1.

(1943). Amer. Heart J., 25, 187.

Tubbs, O.S. (1944). Brit. J. Surg., 32, 1.

Ungerleider, H. E., and Gubner, R. (1942). Amer. Heart J., 24, 494.

Vedoya, R., Gonzalez Videla, J., and Albanese, A. R. (1942). Revist. Argent. Card., $9,94$.

Warren, J. C. (1886). The Healing of Arteries after Ligature in Man and Animals, New York, p. 124.

Wells, H. G. (1908). Amer. J. med. Sci., 136, 381.

White, P. D. (1928). J. Amer. med. Ass., 91, 1107.

Williams, E. C. (1904). Rep. Soc. for Study Dis. of Child., 4, 310.

Wilson, M. G., and Lubschez, R. (1942). J. Padiat., 21, 23.

Zinn, W. (1898). Berlin klin. Wschr., 35, 433.

* Owing to the restricted library facilities of war-time, I have not been able to consult and personally verify this reference. 